University of New Hampshire

University of New Hampshire Scholars' Repository

Fall 1980

\title{
EFFECTS OF A HEPATIC TOXIN FROM THE CYANOPHYTE, MICROCYSTIS AERUGINOSA
}

THOMAS LEE FOXALL

University of New Hampshire, Durham

Follow this and additional works at: https://scholars.unh.edu/dissertation

\section{Recommended Citation}

FOXALL, THOMAS LEE, "EFFECTS OF A HEPATIC TOXIN FROM THE CYANOPHYTE, MICROCYSTIS AERUGINOSA" (1980). Doctoral Dissertations. 2316.

https://scholars.unh.edu/dissertation/2316

This Dissertation is brought to you for free and open access by the Student Scholarship at University of New Hampshire Scholars' Repository. It has been accepted for inclusion in Doctoral Dissertations by an authorized administrator of University of New Hampshire Scholars' Repository. For more information, please contact Scholarly.Communication@unh.edu. 


\section{INFORMATION TO USERS}

This was produced from a copy of a document sent to us for microfilming. While the most advanced technological means to photograph and reproduce this document have been used, the quality is heavily dependent upon the quality of the material submitted.

The following explanation of techniques is provided to help you understand markings or notations which may appear on this reproduction.

1. The sign or "target" for pages apparently lacking from the document photographed is "Missing Page(s)". If it was possible to obtain the missing page(s) or section, they are spliced into the film along with adjacent pages. This may have necessitated cutting through an image and duplicating adjacent pages to assure you of complete continuity.

2. When an image on the film is obliterated with a round black mark it is an indication that the film inspector noticed either blurred copy because of movement during exposure, or duplicate copy. Unless we meant to delete copyrighted materials that should not have been filmed, you will find a good image of the page in the adjacent frame.

3. When a map, drawing or chart, etc., is part of the material being photographed the photographer has followed a definite method in "sectioning" the material. It is customary to begin filming at the upper left hand comer of a large sheet and to continue from left to right in equal sections with small overlaps. If necessary, sectioning is continued again-beginning below the first row and continuing on until complete.

4. For any illustrations that cannot be reproduced satisfactorily by xerography, photographic prints can be purchased at additional cost and tipped into your xerographic copy. Requests can be made to our Dissertations Customer Services Department.

5. Some pages in any document may have indistinct print. In all cases we have filmed the best available copy.

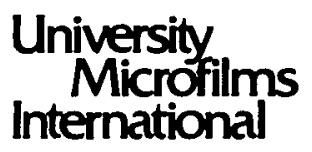

300 N. ZEEB ROAD, ANN ARBOR, MI 48106

18 BEDFORD ROW, LONDON WCIR AEJ, ENGLAND 
FOXALL, THOMAS LEE

EFFECTS OF A HEPATIC TOXIN FROM THE CYANOPHYTE, MICROCYSTIS AERUGINOSA

PH.D.

\section{University} Microfilms

International 300 N. Zeeb Road, Ann Arbor, MI 48106 
PLEASE NOTE:

In all cases this material has been filmed in the best possible way from the available copy. Problems encountered with this document have been identified here with a check mark

1. GTossy photographs

2. Colored illustrations

3. Photographs with dark background

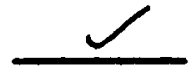

4. Illustrations are poor copy

5. Opint shows through as there is text on both sides of page

6. Indistinct, broken or small print on several pages

7. Tightiy bound copy with print lost in spine

8. Computer printout pages with indistinct print

9. Page(s) lacking when material received, and not available from school or author

10. Page(s)_ seem to be missing in numbering only as text follows

11. Poor carbon copy

12. Not original copy, several pages with blurred type

13. Appendix pages are poor copy

14. Original copy with light type

15. Curling and wrinkled pages

16. Other

University

Microfilms

International 
EFFECTS OF A HEPATIC TOXIN FROM THE CYANOPHYTE,

\title{
MICROCYSTIS AERUGINOSA
}

by

Thomas L. Foxa11

B.S., Lebanon Valley College, 1968

M.S., University of Bridgeport, 1975

\author{
A THESIS \\ Submitted to the University of New Hampshire \\ in partial Fulfillment of \\ the Requirements for the Degree of \\ Doctor of Philosophy \\ in \\ Zoology
}

September, 1980 
This thesis has been examined and approved.

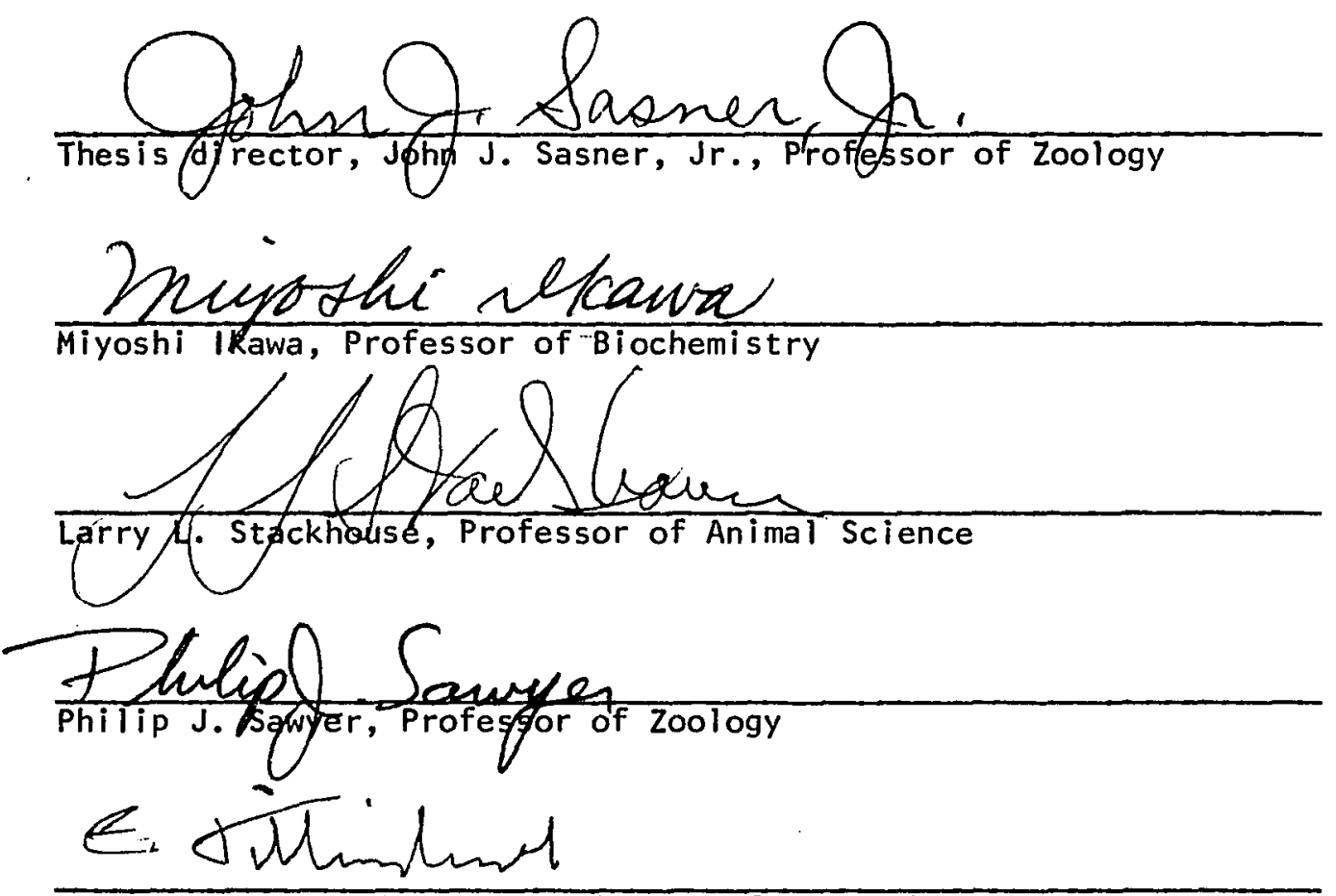

Edward K. Tillinghast, Associate Professor of Zoology

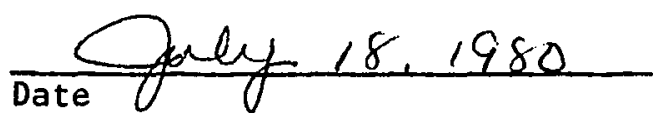




\section{ACKNOWLEDGMENTS}

I wish to express my sincere appreciation and thanks to a number of people who contributed to the completion of this work.

Dr. John J. Sasner, Jr. has been an inspiring mentor who has guided and evaluated my work and provided not only the laboratory space and materials needed, but has helped me to develop many ideas into fruitful experiments. He has given me the chance to broaden my scientific experience and has become a good friend.

Dr. Charles $W$. Walker has provided me with much of the instrumentation for the histological and ultrastructural preparations and has given his valuable advice on light and electron microscopy.

Dr. Richard G. Strout allowed me to work in his cell and tissue culture laboratory where he shared his equipment, supplies and expertise with me. I appreciated his welcome and generosity.

Dr. Miyoshi Ikawa has made his laboratory facilities and advice freely available to me.

Marilyn Ecker has provided advice and technical assistance on the preparation and examination of samples using scanning electron microscopy.

My wife Phyllis has not only given me her encouragement and devotion but has provided for us financially. Her hard work was a great contribution.

This research was supported by a grant from the Office of Water Research and Technology, United States Department of the Interior as authorized under the Water Research and Development Act of 1978, Public Law 95-467, through the Water Resources Research Center of the University of New Hampshire. 


\section{TABLE UF CONTENTS}

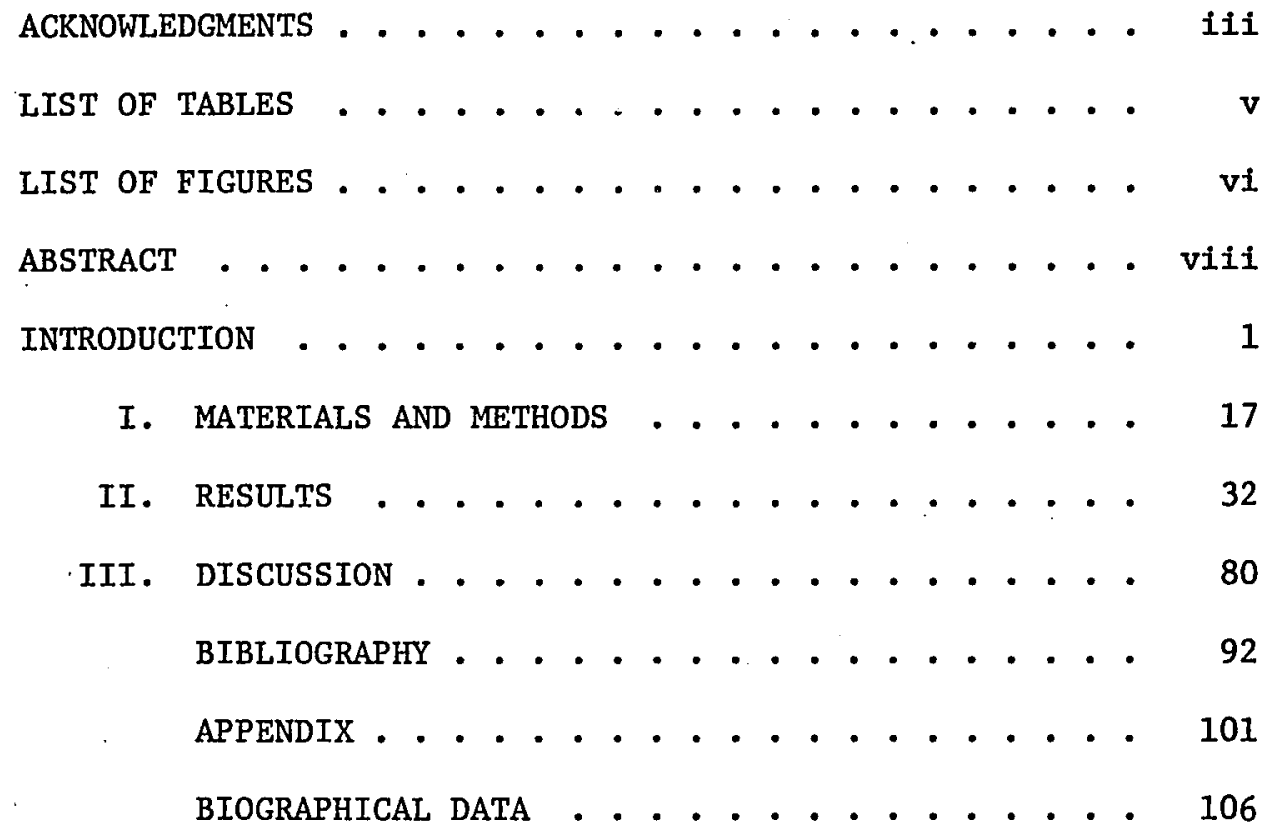




\section{LIST OF TABLES}

1. Amino Acid Composition of Toxic Peptide(s)..... 10

2. Liver Weight and Volume Measurements . . . . . 36 


\section{LIST OF FIGURES}

1. Kezar Lake, North Sutton, New Hampshire . . . . . 48

2. A Colony of Toxic M. aeruginosa cells . . . . . . 48

3. Scanning Electron Micrographs of Toxic $\underline{\text { M. }}$ aeruginosa 50

4. Histological Preparations of Mouse Liver Tissue . . . 52

5. Histological Preparations of Mouse Liver Treated with Toxic Extracts from the NRC-1 Strain of M. aeruginosa . . . . . . . . 54

6. Diagrams Illustrating the Areas of Mouse Livers Examined Histologically and Ultrastructurally 56

7. Untreated Control Mouse Liver Cells . . . . . . 58

8. Mouse Liver Cells Treated with Extracts of

Non-toxic M. aeruginosa for 60 Minutes . . . 60

9. Mouse Liver Exposed to Toxic NRC-1 Extract

for 60 Minutes ............ 62

10. Mouse Liver Exposed to Toxic NRC-1 Extracts

for 60 Minutes . . . . . . . . . 64

11. Mouse Liver Acutely Poisoned by Toxic Extracts of

M. aeruginosa from Kezar Lake, NH . . . . 66

12. Mouse Liver Acutely Poisoned by Toxic Extracts of

M. aeruginosa from Kezar Lake, NH . . . . 68

13. Mouse Liver Exposed to Toxic NRC-1 Extract for

40 Minutes ............... . 70

14. Mouse Liver Exposed to Toxic NRC-1 Extract for

40 Minutes ............... 72 
15. Mouse Liver Exposed to Toxic NRC-1 Extract

for 20 Minutes............ 74

16. Mouse Liver Tissue Exposed to Toxic NRC-1 Extract

for 10 Minutes ............ 76

17. Primary Cultures of Explants from Neonatal

Mouse Liver . . . . . . . . . . 78 


\section{ABSTRACT}

Toxic cyanobacteria bloom in eutrophic, freshwater 1akes and ponds and may cause environmental, health and recreational problems during or after the massive growth of these microorganisms. Microcystis aeruginosa is commonly involved in freshwater blooms and one of its toxins (microcystin) causes liver damage in birds and mammals. This study has determined the specific site of action of microcystin and characterized the hepatic damage at the ultrastructural level. Histological changes in centrilobular regions of liver tissue were noted after intraperitoneal administration in mice. Hepatic sinusoidal epithelial and hepatocyte plasma membranes ruptured with the release of cellular components that pooled with blood. Mitochondria appeared swollen but there were no obvious distortions of other organelles. Extensive vesiculation of membrane fragments was observed. Hepatic damage caused massive hemorrhaging into the liver where blood and cell debris accumulated and produced a significant increase in liver weight.

Primary cultures of hepatocyte microexplants from pre- and postnata1 mice and rats were exposed to microcystin but in vitro effects were not observed. In vitro experiments demonstrated that young animals were not sensitive to the toxin but developed sensitivity as they matured.

Microcystin was shown to be very specific in its site of action since it had no antibiotic activity against green algae, yeast, or bacteria and was non-toxic to certain zooplanktors, crustacea, amphibians and teleosts. Electrical or mechanical 


\author{
activity in isolated nerve, nerve-muscle and cardiac preparations \\ also was not effected. The toxins employed in this study came \\ from cultured cells and naturally occurring blooms and gave \\ identical results in all experiments.
}




\section{- INTRODUCTION}

When freshwater ponds and lakes become eutrophic, whether naturally or through man's intervention, phytoplankton blooms of various algae and/or cyanobacteria are likely to occur. Physical and chemical conditions in freshwater environments which favor the growth of unicellular organisms are high nitrogen and phosphorus concentrations, high dissolved bicarbonates to provide carbon dioxide reserves and surface temperatures above $25^{\circ} \mathrm{C}$ (Prescott, 1948). Such conditions may occur in a body of water and result in a dense green coloration (Fig. 1) and in addition may produce a thick surface scum of algae. Freshwater phytoplankton blooms may be essentially monospecific or consist of several species and some of these may be the source of potent toxins.

All toxic algae described to date are from five phy?.a: Pyrrhophyta (dinoflagellates), Chrysophyta (phytoflagellates), Cyanophyta (blue-green algae), Chlorophyta (green algae), and Rhodophyta (red algae), (Collins, 1978). The so called blue-green algae are actually more procaryotic than eucaryotic and because of their close morphological and biochemical similarities to bacteria (Echlin, 1966), they will, henceforth, be called cyanobacteria or cyanophytes. The latter are ubiquitous and bloom conditions associated with them occur widely. Gorham (1966), cited references describing the poisoning of wild and domestic animals in Argentina, Australia, Bermuda, Brazil, Finland, Morocco and North America. In Canada, blooms were reported for Alberta, Ontario, Manitoba and Saskatchewan. In the United States similar blooms and their effects 
were reported for Illinois, Iowa, Michigan, Minnesota, North and South Dakota, Wisconsin (Gorham, 1966) and in New Hampshire (Sawyer, et al., 1968). There are approximately fifty genera of freshwater cyanobacteria, but only seven toxic species have been described. In North America the most commonly occurring toxic forms are Anabaena flos-aquae, Aphanizomenon flos-aquae, and Microcystic aeruginosa, a.k.a. Anacystis cyanea (Moore, 1977; Drouet and Daily, 1956). All three of these species occur in New Hampshire in both toxic and non-toxic forms.

Environmental problems may occur when cyanobacteria are involved in freshwater blooms. A critical time during the bloom occurs when dense concentrations of cells decompose naturally or when aided by the cosmetic use of algicides (e.g. copper sulphate) by state and/or federal agencies concerned with the control of water quality. The decomposition products plus toxic cellular materials released into the water, when the cells break up, may cause death or illness to mammals, birds and fishes, and may reduce water quality for animal (including human) consumption and recreational purposes.

Toxic strains of Anabaena flos-aquae and Aphanizomenon flosaquae produce potent neuromuscular poisons that effect the neuromuscular junction (endplate) and block membrane excitability, respectively (Carmichae1, 1975; Sasner, 1973). Both toxins affect mobility and coordination in animals and death occurs from paralysis and subsequent respiratory failure. Microcystis aeruginosa, on the other hand, produces a toxin called Fast Death Factor (FDF), (Hughes, et a1., 1955; Bishop, et a1., 1959) and later called microcystin 
(Konst, et al., 1965). The previously undescribed site of action of this toxin from Microcystis aeruginosa is the focus of this study.

Drouet and Daily (1956) attempted to change the nomenclature of the genus Microcystis to Anacystis and claimed that the organism of interest in this study should be called Anacystis cyanea. I have chosen to use the name Microcystis aeruginosa Kutz. emend. Elenkin,because it is firmly entrenched in the literature. This species is a planktonic form of small spherical cells $(3.5-7.0$ um diameter) that may occur singly or in pairs, separate, or as various shaped colonies embedded in a colorless, gelatinous mass. The larger colonies are either hollow, concave or spongiform (Stephens, 1949) and may be visible to the unaided eye as yellowgreen flakes in the water column. In undisturbed water these colonies may rise to the surface and form a thick "pea soup" colored scum (Fig. 2). The literature on $\underline{M}$. aeruginosa and its toxins describes intermittent blooms in the United States (Fitch, et al., 1934; Maloney and Carnes, 1966), South Africa (Steyn, 1945; Stephens, 1949), Russia (Vinberg, 1954; Kirpenko, et al., 1975), Canada (Hughes, et a1., 1955), Australia (McBarron and May, 1966; May, 1970) and England (Heaney, 1971). Judging from the 1iterature and the author's field experience, it appears that toxic strains are more prevalent than reports indicate. Poisonous blooms may occur without positive identification of the causative organisms and more than one toxic species of cyanobacteria may be present at a time.

Blooms of Microcystis aeruginosa are not always toxic. Field samples may vary in potency with season and location. Laboratory 
monospecific cultures vary in toxicity with several physical and chemical factors. Simpson, et al., (1958) reported toxin in only 2 of 9 strains tested; in one study Gorham (1962) found 8 of 19 strains to be toxic and in another study (Gorham, 1964) reported fewer than one third of 28 isolates contained toxin. The latter author found one of two cultures from the same strain (NRC-1) contained measurable amounts of toxin, while the other did not. Strains of $\underline{M}$. aeruginosa were heterogeneous for toxin production and toxicity may be related to a symbiotic-like relationship with other bacteria found in the surrounding gelatinous mass (Fig. 3). It was even suggested that intracellular viruses may be related to toxicity in these cyanophytes (Anonymous, 1977). Gorham (1964) grew isolated bacterial contaminants from $\underline{M}$. aeruginosa cultures, and he found these were either non-toxic or produced symptoms different from those associated with fast death factor (FDF). He concluded that the cells of $\underline{M}$. aeruginosa were the primary source of the toxin. Earlier and later studies supported the contention that the active material was an endotoxin. Potency increased by as much as four times when cells were disrupted by freezing and thawing, sonic disintegration, or incubating overnight in closed containers at high temperatures $\left(37^{\circ} \mathrm{C}\right)$. The lysed cells were toxic whereas the whole (intact) cells and the medium supporting growth of $\underline{\text { M. aeruginosa }}$ were not toxic (Wheeler, et a1., 1942; Hughes, et al., 1955; Heaney, 1971). Similar studies using cells from natural blooms also supported this observation, i.e. FDF toxicity was associated with the $\underline{M}$. aeruginosa cells.

Hughes, et al. (1955), reported the presence of two different toxins isolated from a bloom of Microcystis aeruginosa in Ontario, 
Canada. Using ultraviolet irradiation on unialgal cultures, they were able to cause fast deaths ( 1 hour) and slow deaths (24-48 hours) in mice. Further work showed the presence of a slow death factor (SDF) in addition to the already known fast death factor (FDF) in the same samples, each with its own unique symptoms. (Hughes, et al., 1958). When lethal amounts of FDF were present, the effects of the SDF were obscured. Further confirmation of the SDF came from Thompson et al. (1957), when they found a strain of M. aeruginosa containing no FDF, but only SDF. The latter was produced by a bacterium associated with the cyanobacterial cells. The slow death factor (SDF) was defined as the toxin that produced survival times ranging between 4 and 24 hours in mice and was produced by bacteria associated with $\underline{\text { M. }}$ aeruginosa. The fast death factor (FDF), produced death times in mice usually within 1 hour and came from the cyanobacterial cells. In addition to these two toxins, Aziz (1974) described a diarrheagenic substance from a strain of $\underline{M}_{\text {. }}$ aeruginosa isolated from a pond in Bangladesh. The active material was a non-dialyzable fraction of whole cell lysate and caused fluid accumulation in the small intestine of guinea pigs. Outbreaks of diarrhea in the human population have often been reported in areas where there were blooms of $\underline{M}$. aeruginosa and where no other obvious etiology could be found. Gorham (1962) stated that SDF might be linked to intestinal inflammation in connection with algal poisoning by $\underline{M}$. aeruginosa. The cyanobacterial species of interest in this study is the source of FDF but may have other harmful materials associated with it, i.e. SDF and diarrheagenic factor. Thus, there are toxins, other than FDF, associated with $\mathrm{M}$. aeruginosa, that are not of prime concern in this study. 
Schwimmer and Schwimmer (1964) reviewed cases of poisoning in wild and domestic mammals and birds that consumed water containing dense concentrations of cyanophytes. Domestic animals most affected were cattle, sheep and to a lesser extent, turkeys. Thousands of sheep and cattle were killed after drinking from a bloom of $\underline{M}$. toxica in the Vaal Dam region near Johannesburg, South Africa. Other animals, i.e. horses, mules, donkeys, dogs, hares, poultry and water birds were found dead nearby and may a1so have succumbed to the effects of the Microcystis bloom (Stephens, 1949). More definitive laboratory studies revealed that sheep, cattle (including calves), guinea pigs, rabbits, cats, rats, mice and chickens were sensitive to the effects of the toxins (Gorham, 1962; Mason and Wheeler, 1942; Konst, et al., 1965). Intraperitoneal (i.p.) lethal doses for domestic ducks were 4 times that for laboratory animals and the ducks survived the highest oral doses used. Waterfowl were also resistant to orally administered microcystin (FDF) but were sensitive to i.p. doses (Gorham, 1962).

A narrow range of values for minimum lethal dose, $\mathrm{LD}_{100}$ and $\mathrm{LD}_{50}$ (doses that $\mathrm{kill} 100 \%$ and $50 \%$ of toxin-challenged animals, respectively) appears in the literature. Gorham (1964), established that the survival time for a minimum lethal dose of FDF in $20 \mathrm{~g}$ mice was 30 to 60 minutes. For bioassay purposes in comparative studies one mouse unit (MU) was defined as the amount of toxin (FDF) required to kill 20 gram mice in 60 minutes after intraperitoneal injection. Several studies over a period of 20 years showed that lethal doses for mice challenged i.p. with FDF varied between 40 to $160 \mathrm{mg}$ lyophilized toxic material/kg body weight (Mason and Wheeler, 1942; 
Shelubsky, 1950; Hughes, et al., 1954; Gorham, 1962). Partially purified extracts produced lethal effects at all levels between 0.5 to $0.1 \mathrm{mg} / \mathrm{Kg}$ body weight (Bishop, et al., 1959; Murthy and Capindale, 1970). However, the oral lethal dose for mice and larger mammals was 5 to 50 times the lethal i.p. dose, although the toxin produced the same symptoms when given by either method (Olson, 1951; Simpson, et al., 1958; Gorham, 1964; Konst, et al., 1965; Heaney, 1971). These discrepencies in potency are not great when compared to the action of other biotoxins and may be accounted for by: a) differences in the purity of samples; b) variation in amounts of toxin/cell; c) variable sensitivities of the test animals. used; and d) differences in the methods of toxin preparation prior to testing.

When dead fish were found associated with natural blooms of Microcystis aeruginosa, the question arose as to the toxins effect on aquatic animals. Laboratory studies by Maloney and Carnes (1966) employed a butanol extract $\left(\mathrm{LD}_{100}\right.$ in mice $\left.=3 \mathrm{mg} / \mathrm{Kg}\right)$ to challenge three teleost species, (fathead minnows, Pimephales promelas, carp, Cyprenus carpio, and guppies, Lebistes reticulatus), a zooplankter crustacean (Daphnia magna) and diatoms (Navicula minima). The extracts were not toxic to any of the species tested at the dose levels used (10 mg/L). Solomatina and Matchinskaya (1972) reported changes in the quantity of extracted free and bound amino acids from whole fish (Leuciscus idus L.) exposed to "lethal concentrations" of cyanophyte mixtures that were predominantly $\underline{\mathrm{M}}$. aeruginosa. They noted a significant increase in free amino acids, while many amino acid concentrations decreased in protein hydrolysates. Malyarevskaya, 
et a1., (1972) used mixed algal cultures (predominantly … aeruginosa) and reported that the introduction of a lethal quantity of "algae" (0.6-5.0 gm./L) into aquaria killed several species of fish within 6 to 64 hours. Survival times were inversely related to the quantity introduced and also depended on the state of decomposition of the materials (including cyanobacteria). They further noted changes in "energy consumption", nitrogen metabolism, amino acid composition, thiaminase activity and thiamine content.

The first attempt at isolation and chemical characterization of microcystin was done by Louw (1950) using a strain of Microcystis from a South African lake. The cells were lysed with chloroform, filtered, evaporated to a thick residue and extracted with acetone. The resulting material gave a positive reaction for alkaloids and a molecular weight of 220 daltons was determined for the hydrochloride salt. The central nervous system and liver of poisoned animals was affected by this active material. Another isolation of toxin from the NRC-1 strain of $\underline{M}$. aeruginosa was accomplished from laboratory cultures by Bishop, et al. (1959). The active material was extracted from cells with methanol, $95 \%$ ethanol or $0.1 \mathrm{~N}$ sodium carbonate. The alcohol extracts, after dialysis, yielded the free acid form of the toxin, while the latter method produced an active extract as the sodium salt. Both of these produced the same symptoms in mice as aqueous extracts of lyophilized cells. The dialyzable material (FDF) was further purified by paper electrophoresis to yield a toxic peptide (1ater called microcystin, Konst, et al., 1965) with an $\mathrm{LD}_{50}$ of $0.466 \pm 0.013 \mathrm{mg} / \mathrm{Kg}$ body weight, in mice. Again, all the activity in crude lyophilized extracts was accounted for by this peptide. The 
resistance to digestion by several proteolytic enzymes, and the inability to form $\mathrm{N}-2$, 4-dinitrophenyl derivatives, indicated that the active substance was a cyclic peptide. In addition, the presence of $D$-serine was established by removal with D-amino acid oxidase, while none of the other amino acids were affected, indicating that they were in the L-configuration. Murthy and Capindale (1970) also used the same NRC-1 strain of $\underline{M}$. aeruginosa to produce an ammonium salt of the toxin. The isolation was based on solvent extraction and elution from DEAE-Sephadex A-25 and resulted in a white solid that was chromatographically and electrophoretically homogeneous. The isolated toxin gave positive reactions with ninhydrin and with the t-butyl hypochlorite-starch-iodine modification of the Rydon-Smith test. This suggested that the molecule was a peptide with a free amino group. In addition to the seven amino acids reported by Bishop, et al. (1959), they found an additional seven, including tyrosine, proline, arginine, threonine, glycine, isoleucine, and phenylalanine, (Table 1). This toxic peptide had an $\mathrm{LD}_{50}$ of $0.1 \mathrm{mg} / \mathrm{Kg}$ body weight (i.p.) in mice. The differences in the results of the two isolation studies have not been resolved, however, Bishop, et al. (1959), suggested that both peptides were probably derived from the same toxic material present in the $\underline{M}$. aeruginosa cells. The accumulated information thus far suggests that microcystin is a homeomeric peptide with an estimated molecular weight between 1300 and 2600 daltons. In a more recent study (Kirpenko, et al., 1975), a molecular weight of 19,400 daltons was ascribed to a biologically active material extracted with ion exchange resin $(A B-22)$ from mixed algal samples containing $\underline{M}$. aeruginosa. 
Table 1.

Amino acid composition of toxic peptide(s) from $\underline{M}$. aeruginosa.

\begin{tabular}{|c|c|c|c|c|}
\hline \multicolumn{2}{|c|}{ Bishop, et al., 1959} & \multirow[b]{2}{*}{ Mole Ratio } & \multicolumn{2}{|c|}{ Murthy and Capindale, 1970} \\
\hline Amino acid & Configuration & & Amino acid & Configuration \\
\hline \multicolumn{2}{|c|}{ Aspartic acid - L } & 1 & \multicolumn{2}{|c|}{ Aspartic acid - L } \\
\hline \multicolumn{2}{|c|}{ Glutamic acid - L } & 2 & \multicolumn{2}{|c|}{ Glutamic acid - L } \\
\hline \multicolumn{2}{|l|}{ Ornithine } & 1 & Ornithine & $-L$ \\
\hline \multicolumn{2}{|l|}{ Serine } & 1 & Serine & $-D$ \\
\hline \multicolumn{2}{|l|}{ Alanine } & 2 & Alanine & $-\mathrm{L}$ \\
\hline \multicolumn{2}{|l|}{ Leucine } & 2 & Leucine & $-\mathrm{L}$ \\
\hline \multirow[t]{8}{*}{ Valine } & $-\mathrm{L}$ & 1 & Valine & $-L$ \\
\hline & & 1 & Arginine & $-\mathrm{L}$ \\
\hline & & 1 & Threonine & $-I$ \\
\hline & & 1 & Proline & $-L$ \\
\hline & & 1 & Glycine & $-L$ \\
\hline & & 1 & Isoleucine & $-L$ \\
\hline & & 1 & Tyrosine & $-L$ \\
\hline & & 1 & Phenylalanir & $-L$ \\
\hline \multicolumn{3}{|c|}{$L D_{50}=0.5 \mathrm{mg} / \mathrm{Kg}$ body wt. } & \multicolumn{2}{|c|}{$\mathrm{LD}_{50}=0.1 \mathrm{mg} / \mathrm{Kg}$ body wt. } \\
\hline
\end{tabular}


Major studies on the physiological effects and pathology of Microcystis aeruginosa were done at least 25 years ago. Mason and Wheeler (1942) reported that the administration of toxin (i.p.) to mice produced a 20 minute latent period, followed by pallor, lowered blood pressure and body temperature, hyperglycemia and tachycardia, and death by respiratory failure. During the latter stages of involvement the hematocrit, hemoglobin concentration, $\mathrm{RBC}$ count and total serum protein were all lowered. Autopsy of one animal revealed a severely congested liver and dilation of the right side of the heart. The toxin(s) caused systolic arrest in perfused amphibian heart preparations but did not alter oxygen consumption values of liver, kidney, diaphragm or brain brei.

Ashworth and Mason (1945) challenged adult rats with a "maximum" sublethal dose of Microcystis aeruginosa toxin and measured gross organ changes over a period of 30 days. The authors noted an enlarged, tense or turgid, "redder than normal", liver within 30 minutes after toxin administration. Liver size increased (approximately $25 \%$ by weight) along with blood volume surrounding parenchymal cells after 3 to 6 hours, at which time the tissue was soft and friable. No gross changes were observed in other organs. After 2 to 3 days liver size was reduced by $1 / 3$, was colored yellow, mottled, and had a soft consistency. At this time, other tissues were also slightly icteric or jaundiced, the kidneys were softer and larger than normal, the urine was dark yellow, and blood clotting time increased. Fluid did not accumulate in serous cavities and the lungs appeared normal with only a few petechial hemorrhages. The rats lost weight and exhibited a general pallor. After 5 days, the 1iver 
and other organs appeared to be normal in color, size and consistency. After 30 days, no gross changes were noted in any organs and the liver showed neither nodular regeneration, fibrosis, no cirrhosis. Ashworth and Mason (1945) also reported on the histological changes versus time after toxin administration (i.p.) in rats. Within 15 minutes liver cells were swollen, hepatocyte cytoplasm was more granular and in some areas was hydropic. Clear halos were noted in the perinuclear cytoplasm, fat droplets appeared in the center of lobules and the sinusoids appeared slightly distended with RBC's. Coagulative necrosis was suggested. After 4 hours there was marked necrosis in the centers of lobules, complete dissociation of liver cords with remnants of liver cell bodies lying free in the blood in the confluent sinusoids. Isolated cells were swollen and rounded and the cytoplasm was hyalinized and eosinophilic. Nuclei were pyknotic or failed to stain. Sinusoids at the lobule center were markedly distended, apparently confluent and filled with RBC's. Actual destruction of sinusoidal epithelium was noted in some instances.

After 24 to 48 hours test animals showed signs of recovery. In 3 to 5 days the liver lobules were normal in size and arrangement and mitotic figures were observed, indicating regeneration. Liver restoration was completed after 28 days.

The heart (after 2 hours) showed some swelling and an increased granularity of fibers. Slightly swollen and hyalinized muscle fibers were present in the left ventricle. A few small hemorrhages were found below the endocardium and in the myocardium; this was most marked at 4 hours. No cardiac changes were noted after 3 to 5 
days. The lungs were only slightly involved; there was equivocal alveolar capillary involvement that consisted of focal, slight alveolar hemorrhages. The kidney showed changes after 20 minutes with marked patchy, cortical hyperemia, swelling, increased granularity and loss of the distinct luminal border of the tubular epithelium. The spleen, adrenal glands and brain showed no histological changes. In regards to the toxins' effects on organs other than the liver these authors state:

"Its action, however, is not confined to the liver, but leads also to cellular degeneration and necrosis in a much less intense form in other organs particularly the heart and kidneys . . ."

Prescott (1949) cites Steyn (1945) who reported that the toxin from Microcystis species produced pathological conditions such as constipation and drop in milk production in cattle, sheep, and other animals.

The effects described above were reported prior to: a) the biological use of transmission and scanning electron microscopy, b) the establishment of routine cell and tissue culture techniques, c) the discovery of SDF and diarrheagenic toxins in addition to FDF (microcystin) and d) the chemical purification and identification work of Murthy and Capindale (1970) and Bishop, et al., (1959). More recent work by Konst, et al. (1965) on the gross effects of microcystin showed decreased peripheral circulation and a concentration of blood in the viscera. Heart morphology and function was normal in lambs and birds. No pronounced changes in lungs, intestine, or kidneys were observed except for some congestion in these organs in chickens and ducks. The lack of hematological changes in mice suggested that decreased prothrombin resulting from 
liver damage may be the cause or decreased clotting time in animals. They also noted a close correlation between the symptoms from naturally occurring Microcystis aeruginosa and laboratory cultures (NRC-1). Histological work showed cells in the central zone of each lobule were necrotic or replaced by pools of blood. At the periphery of each lobule the parenchymal cord structure was retained but showed signs of degeneration.

Heaney (1971) also demonstrated hepatic damage in white mice within 15 minutes after i.p. injection of lethal quantities of Microcystis aeruginosa cells. The livers were darker than normal, had congestion in the centrilobular area, swollen cells, and localized subcapsular hemorrhaging. Small hemorrhages were noted in the lungs but no other organs were affected at this time. After 30 minutes the livers were engorged with blood, were darker colored, and displayed increased congestion in central veins, and centrilobular necrosis in almost every lobule. Subcapsular hemorrhaging occurred and Kupfer cells began to swell in intralobular areas. There was swelling of convoluted tubules in the kidney and fibrinoid necrosis of the pulmonary artery in the lungs. The left ventricular wall displayed swelling of individual fibers. Gorham (1962) had previously reported swelling in the right ventricle.

Orlovski and Kirpenko (1976) reported that the biological oxidation of carbohydrates in warm blooded animals was altered by toxin(s) from a dense growth of blue-green algae collected from a water supply in Russia.

The past work has left ambiguous and conflicting information about microcystin (FDF) in the literature, some of which does not 
agree with present knowledge. These anomalies will be discussed below, in light of the results of this study. Most of the former research was done with materials from cultures, field samples or extracts that may have contained mixtures of microcystin, SDF, and diarrheagenic factor. Although histological changes resulting from acute and chronic doses of toxin(s) were described, the cellular, subcellular and biochemical changes that are the ultimate cause of tissue damage have not been elucidated.

The role of microcystin in animal deaths has been attributed to effects at the organ, tissue and cell levels of organization, e.g. acute hepatic insufficiency (hepatic coma), shock, renal damage, cardiovascular damage, respiratory failure, or depression of cellular metabolism in body tissues. The probabilities of these and other causes of death in animals will be discussed.

Several common characteristics were noted from the literature regarding the possible effects of microcystin in mammals. These include: (1) the liver as a target organ, (2) the engorgement of the liver with blood, (3) the destruction of hepatocytes, and (4) the rapid onset of ce11 degeneration and necrosis.

The primary goals of this study concern the specific site of action of microcystin in mammals. Specific attempts were made to: a) characterize hepatic lesions at the cellular/subcellular level, b) examine effects on isolated target cells, and c) compare effects from cultured and natural strains of Microcystis aeruginosa. Secondary, and more general goals include a survey of the effects of the toxin on: a) freshwater animals (vertebrate and invertebrate) that may be exposed to $\underline{M}$. aeruginosa in nature, b) microorganisms, and c) neuro- 
muscular systems. In addition, a convenient procedure for partial purification of microcystin was an objective to facilitate the other goals of the project. 
MATERIALS AND METHODS

Microcystis aeruginosa: Sources, Field Collection, Laboratory

Samples of Microcystis aeruginosa used in this study were gathered from several sources over the past nine years. A starter culture of the toxic NRC-1 strain was obtained from Dr. Paul R. Gorham, Edmonton, Alberta, Canada via Dr. John H. Gentile, National Marine Water Quality Laboratory, West Kingston, Rhode Island and cultured in our laboratory between 1970 and 1972 by Mr. David T. Richardson. Field samples of toxic cells were harvested from Kezar Lake, North Sutton, New Hampshire during the summers of 1977, 1978, and 1979 and used for comparative studies versus the NRC-1 strain. Samples of non-toxic strains of $\underline{M}$. aeruginosa were obtained from the U.S. Environmental Protection Agency, National Environmental Research Center, Corvallis, Oregon; the Culture Centre of Algae and Protozoa, Cambridge, England; and Dr. Alan L. Baker, Botany Department, University of New Hampshire. The latter, non-toxic strain was isolated from Lake Mendota, Wisconsin circa 1958 by Dr. George Fitzgerald, Department of Botany, University of Wisconsin and subsequently maintained by Dr. Joseph Shapiro, Limnological Research Center, University of Minnesota prior to coming to New Hampshire in 1972. All laboratory cultures were unialgal but not axenic and were grown in the modified ASM-1 medium of Carmichael and Gorham (1974). Bulk quantities of cells, from the field or laboratory, were harvested using one of two centrifugation methods. When the cells occurred singly, in doublets, or small colonies (NRC-1 strain), they were spun 
from the medium into a residual pellet. This was done using a Sorvall RC-2B Centrifuge (5000 rpm) with a KSB Continuous Flow System ( $150 \mathrm{mls} / \mathrm{min}$ ). When large clumps or colonies occurred, these would float to the surface and centrifugation was used to separate the more dense medium from the cell material. After harvesting, the cells were stored either wet or in the lyophilized state at $-15^{\circ} \mathrm{C}$. Toxic material from the NRC-1 strain was stored for more than eight years with no apparent loss of potency.

\section{S.E.M. - Preparative Procedures for Cyanobacteria}

Samples of Microcystis aeruginosa were prepared for examination with the scanning electron microscope using two, closely related methods: 1) Cells or colonies were collected on $0.45 \mu \mathrm{m}$ sterile Millipore filter discs by routine filtration of culture or natural bloom material. The collected cells were washed with either distilled water or phosphate buffer $(0.1 \mathrm{M}$; $\mathrm{pH} 7.0)$. The filter discs were placed in small petri dishes filled with $3 \%$ buffered glutaraldehyde fixative for 20 minutes. After several rinses, the samples were fixed in $1 \%$ osmium tetroxide for 20 minutes, dehydrated with a series of ethanol solutions $(35 \%, 50 \%, 70 \%, 95 \%, 100 \%$ and 100\%) for 15 minutes each and immediately critically point dried in a Samdri instrument with liquid $\mathrm{CO}_{2} \cdot$ 2) Other cell samples were fixed in solution by adding the glutaraldehyde to the aqueous sample for 20 minutes. After this primary fixation, the cells were then filtered down onto $0.45 \mu \mathrm{m}$ sterile Millipore filter discs, washed, and treated as above. The samples from both procedures were mounted on aluminum stubs, coated with carbon and gold, and 
examined using an AMR 1000A Scanning Electron Microscope. Photographs of the cyanobacteria were taken on Polariod 55 PositiveNegative film.

Toxin Preparation, Bioassay, Potency

Fresh frozen samples were thawed and refrozen 2 or 3 times to ensure cell breakage, while lyophilized materials were reconstituted with distilled water or appropriate Ringer's solution, depending on the animals being tested. Both of these were centrifuged (2500 rpm 10 min.) to remove cell debris prior to use. Centrifugation produced a small, green, non-toxic pellet or residue and a clear, light blue, toxic supernatant. Potency was determined by injecting $1.0 \mathrm{ml}$ of the supernatant, intraperitoneally, into $20 \pm 2$ gram mice and recording symptoms and survival times. The mice $(\mathrm{B} 6 \mathrm{D} 2 \mathrm{~F} 1 / \mathrm{J})$ were obtained from the Jackson Laboratory, Bar Harbor, Maine. These and segregating generations from intercrosses were used as test animals. One mouse unit (MU) of microcystin (FDF), i.e. the amount of toxin needed to kill 20 gram mice in 60 minutes, was found in $1.0 \mathrm{mg}$ of lyophilized extract from both the NRC-1 and Kezar Lake strains of Microcystis aeruginosa. This value converts to $50 \mathrm{mg} / \mathrm{Kg}$ body weight which is within the range of potency reported in the literature (40-160 mg/Kg body weight).

It was not possible to completely purify the polypeptide microcystin, because of the relatively small quantities of lyophilized Microcystis aeruginosa material avallable from laboratory cultures and intermittent natural blooms. Several unsuccessful at tempts at purification employed TLC, paper chromatography, and paper and cellulose acetate electrophoresis in various solvent 
and buffer systems (see Appendix I). In each case, however, the amounts of recovered materials would not permit adequate testing, - again a function of relatively small amounts of crude starting material. Partial purification was achieved, however, using Diaflo Ultrafiltration Membranes (Amicon Corp., Lexington, Mass.) and Immersible Molecular Separators (Millipore Corp., Bedford, Mass.). Toxic samples $(10.0 \mathrm{ml})$ were filtered through the molecular sieves using a magnetic stirrer for constant mixing and nitrogen gas at 30 psi as a driving force. The following sieve sizes were used: $100,000,50,000,30,000,20,000,1,000$ and 500 daltons. In addition, a 10,000 dalton immersible separator was used on house vacuum.

\section{Histology - Survey of Mouse Tissues}

A gross anatomical and histological survey of mouse organs was conducted in an attempt to locate the lesions caused by microcystin (FDF). Al1 mice were maintained under constant conditions of temperature, daylength and diet. The animals were given tap water and Mouse Chow $\$ 5015$ (Ralston Purina) ad libitum. Since the intracellular contents of hepatocytes and other cells may vary with time of day, all animals were injected and sacrificed at approximately the same time of day (11:00 AM). Four mice were given an acute dose ( $1 \mathrm{MU}$ ) of toxin. All major organs were visually examined immediately after death $(1 \mathrm{hr})$ and tissue samples removed for histological examination. These included: liver, lung, spleen, heart, skeletal muscle, stomach, large and small intestine, and kidney. The tissue samples were fixed in $10 \%$ phosphate buffered formalin ( $\mathrm{pH} 7.0$ ) with a fixative:tissue ratio of $10: 1$ (v:v). Histological processing was done by the Veterinary Diagnostic 
Laboratory at the University of New Hampshire. Tissue samples were embedded in paraffin, sectioned at approximately $12 \mu \mathrm{m}$, mounted on glass slides, and stained with hematoxylin and eosin.

\section{Gross Liver Changes}

Two groups of 15 mice $(20 \pm 2 \mathrm{~g})$ were injected, i.p., with 1.0 $\mathrm{m} 1$ of aqueous extract containing $1.0 \mathrm{mg}$ of either nontoxic or toxic material (1 MU). All mice either died or were sacrificed by cervical separation at 60 minutes from the time of injection. The animals were dissected and all liver tissue was carefully removed. The weights and volumes of the whole livers from each animal were recorded to the nearest $0.01 \mathrm{~g}$ and $0.1 \mathrm{ml}$, respectively. The percent of liver:body weight was calculated for each animal and routine statistical analysis of the data was performed for each group. Significance was checked at the 95 and 99 percent confidence levels.

\section{Tissue/Ce1lular/Subcellular Morphology - Mouse Liver}

\section{Toxin-Time Study}

To assess the development of structural damage in liver tissue, a toxin-time study was conducted. A group of mice $(20 \pm 2 \mathrm{~g})$ were challenged, $i . p .$, with $1 \mathrm{MU}(1 \mathrm{mg} / \mathrm{ml})$ of toxin and were sacrificed by cervical separation after 10,20, 40 and 60 minutes. At least 4 mice were used for each time interval and liver tissue was prepared for histological and ultrastructural study. An equal number of control animals were injected with $1 \mathrm{mg} / \mathrm{ml}$ of non-toxic Microcystis aeruginosa extract and liver samples were processed along with the experimental preparations described above. Thus, there were normal 
untreated mouse liver samples, preparations from mice given nontoxic extracts, and preparations from mice given a lethal dose of toxin for varying time periods.

\section{T.E.M. - Preparative Procedures}

Immediately after sacrificing the experimental and control animals, they were dissected to carefully expose the liver. Small slices of the liver were removed using new, acetone-cleaned razor blades and blunt toothpicks. These were placed in a large drop of $0.1 \mathrm{M}$ cacodylate buffered $3 \%$ glutaraldehyde ( $\mathrm{pH} 7.2-7.4 ; 560 \mathrm{~m} 0 \mathrm{sm}$ ) (Polysciences, Inc.) on a sheet of dental wax. The glutaraldehyde fixative contained approximately $0.05 \mathrm{mls}$ of $1 \% \mathrm{CaCl}_{2}$ for each 10 mls of fixative. While the tissues were in the glutaraldehyde, they were cut into smaller pieces, transferred to a fresh drop of fixative, and shaped into cubes of approximately $1 \mathrm{~mm}^{3}$. These were placed into glass vials containing fresh fixative for 2 hours at room temperature. The tissue cubes were then washed nine times, at 5 minute intervals, with cold cacodylate-sucrose solution $(0.1 \mathrm{M}$ disodium cacodylate buffer; $\mathrm{pH} 7.0 ; 400$ m0smols, adjusted with sucrose) and kept overnight at $4^{\circ} \mathrm{C}$. Each vial contained approximately $20\left(1 \mathrm{~mm}^{3}\right)$ tissue cubes in order to provide a suitable fixative: tissue ratio $(v: v)$.

The wash was replaced in the vials with a post-fixative solution of $1.0 \%$ osmium tetroxide $\left(\mathrm{Os}_{4}\right)$ in $0.1 \mathrm{M}$ Millonig's phosphate buffer $\left(\mathrm{pH} \mathrm{7.2)}\right.$ at $4^{\circ} \mathrm{C}$ (Hyatt, 1971), for 1 hour.

The pieces of liver tissue were then dehydrated in the vials by treating with the following ethanol concentrations for 15 minutes 
each: $35 \%, 70 \%, 95 \%, 100 \%$ and $100 \%$. Propylene oxide was added for 15 minutes, then replaced by a 50-50 mixture of complete embedding resin (Epon 812, Polysciences, Inc.) and propylene oxide for 1 hour. The latter was replaced with complete resin and left on the tissues overnight. Continuous rotation (15 rpm) was used for more complete embedding.

Epon 812 is a glycerol-based aliphatic epoxy resin. Dodecenyl succinic anhydride (DDSA) and nadic methyl anhydride (NMA) were added to Epon 812 to make up two stock mixtures. Mixture A contained $66 \mathrm{ml}$ of Epon 812 and $100 \mathrm{ml}$ of DDSA; mixture B contained $100 \mathrm{ml}$ of Epon 812 and $84 \mathrm{ml}$ of NMA. DDSA and NMA are longer and shorter cross linkers, respectively, that produce softer and harder resins. Complete resin consisted of $1 / 2$ mixture $A$ and $1 / 2$ mixture B plus $0.14 \mathrm{ml}$ of 2, 4, 6-tri(dimethylaminomethy1)-pheno1(DMP-30) added per $10.0 \mathrm{ml}$ of the resin mixture. DMP-30 is an amino accelerator used as a catalyst in hardening the resin. The 50-50 mixture of stocks A and B produces a semi-hard block that is well suited to liver tissue.

After embedding, the pieces of tissue were carefully placed on a piece of filter paper to remove excess resin. Two drops of fresh resin were placed into each BEEM (00) capsule for each different animal. Air bubbles were removed, the tissue was placed in the capsules, and a label was inserted, before filling with fresh resin. The capsules were placed in a $60^{\circ} \mathrm{C}$ oven to harden for 72 hours. The capsules were cut open and the blocks of epoxy-embedded tissue were placed in holders and left in a dessicator to cure for several days before trimming and cutting. 
The blocks were trimmed such that only embedded tissue formed a trapezoid (base $0.5 \mathrm{~mm}$ or less). 'Thin sections were cut on a thermal advance Reichert OM-2 ultramicrotome and mounted on 300 and/or $400 \mathrm{mesh}$, acetone-cleaned, copper grids. Only sections with gray, silver, or light gold interference colors were used. The thin sections were stained for 4 minutes in saturated (approximately 2\%) filtered (Whatman No. 1 paper) urany1 acetate. This was an aqueous solution. The grids were inverted onto sma11 drops of uranyl acetate that had been placed on dental wax in a petri dish. Sections were rinsed in doubly distilled water by dipping 10 times into 6 different beakers, then allowed to dry on filter paper. Sections were then stained with Reynold's lead citrate (Hyatt, 1971) for 10-12 minutes using the same procedure as above except that $\mathrm{NaOH}$ pellets were placed on one side of the petri dish to absorb $\mathrm{CO}_{2}$ and prevent lead carbonate precipitation on the sections. Grids were washed as above and again dried on filter paper. Separate petri dishes were used for the two different heavy meta1 stains.

Grids were scanned and sections photographed at low and high magnifications on both the Philips 200 and the JEOL 100 S transmission electron microscopes at the Electron Microscope Facility of the University of New Hampshire. The film used in the electron microscopes was Kodak Electron Image Film 4463. Negatives were printed on Kodabromide single weight papers of varying grades.

\section{Tissue Culture Methods}

Primary hepatocyte cultures were established using liver 
tissues from 4 neonatal mice, 4 ten-day-old mice, 2 adult mice $(20 \mathrm{~g}), 2$ two-day-old rats and 2 ten-day-old rats. The animals were sacrificed by cervical separation, rinsed with $70 \%$ ethanol, and dissected along the mid ventral surface using sterile instruments and techniques. The liver was carefully exposed and the intact gall bladder was excised. The liver was removed into Hank's balanced salt solution and rinsed several times. Hank's salt solution without $\mathrm{CaH}$ and $\mathrm{MgH}$ was added after decanting the balanced solution and the livers were minced with curved scissors and rinsed several times to remove blood cells. Fifteen or twenty $\mathrm{mls}$ of enzyme were added and the tissue suspension was placed in a sterile agitation flask with a magnetic stirring bar. At first, trypsin (1:250)-EDTA $(0.5 \mathrm{gm}-0.2 \mathrm{gm} / \mathrm{l})$ was used but this was discontinued in favor of collagenase $(0.5 \%$ in Hank's w/o Catt and $\mathrm{Mg++}$. The suspension was stirred for 15 minutes, pieces of tissue were allowed to settle, and the cloudy cell suspension was decanted into a sterile, $50 \mathrm{ml}$ plastic centrifuge tube set in ice. Agitation was repeated for 10 minutes and the cell suspension was again decanted. The cells were centrifuged for 10 minutes at $800 \mathrm{rpm}$ 's, the enzyme solution was poured off and the cells were resuspended (with gentle stirring) in medium. In later trials, fetal calf serum was added prior to centrifuging in order to protect the cells from further enzymatic action.

Ce11 counts were made with the vital stain trypan blue in order to determine the number of cells per $\mathrm{ml}$ and estimate viability.

Ce11s were seeded into Leighton tubes and plastic $\mathrm{T}$ flasks 
at concentrations from $5.0 \times 10^{5}$ to $2.0 \times 10^{6}$ per ml. Usually, the higher seeding concentrations were used.

All plasticware used was from Corning and all solutions, media and enzymes were obtained from Grand Island Biological Supply Company, Grand Island, N.Y. All solutions and media were prewarmed to $37^{\circ} \mathrm{C}$.

The Leighton tubes contained a final volume of $2 \mathrm{ml}$ of cell suspension and the $\mathrm{T}$ flasks contained $4 \mathrm{ml}$ final volume. Cultures were placed, loosely stoppered, in $\mathrm{CO}_{2}(5 \%$ in air) humidified incubators at $37^{\circ} \mathrm{C}$. The $\mathrm{pH}$ of the media was monitored by color as all solutions and media contained phenol red as an indicator.

Two media were tried, $M A B 87 / 3$ and $F 12 K$, but the $M A B 87 / 3$ proved more efficient. Various concentrations of heat inactivated fetal calf serum were used, ranging from no serum to trials with $5,10,15$, and $20 \%$. Completely defined medium (no serum) MAB $87 / 3$ was used. This medium was developed specifically for mouse liver cultures by $\mathrm{Dr}$. C. Waymouth and provided a more completely controlled environment for the primary hepatocytes seeded without serum.

Medium was usually changed after 24 hours, but in some experiments the cells were allowed to settle for varying time periods. The medium was changed after allowing the cells to settle.

Toxic and non-toxic Microcystis aeruginosa crude extracts were prepared, evaporated down to approximately $1 \mathrm{ml}$, and then rediluted in the medium to be used (usually $M A B$ 87/3). These solutions were filter sterilized by passing them through a $0.22 \mathrm{um}$ sterile disposable filtering apparatus (Falcon, Oxnard, Ca.) and 
were stored frozen. The toxicity of the media, with toxic and nontoxic additions was tested in mice prior to any cell culture work.

Toxic and non-toxic media solutions were thawed, brought up to culturing temperature $\left(37^{\circ} \mathrm{C}\right)$ and stirred. The media was poured off the cultures and replaced with control or experimental solutions and the cultures were placed back in incubation for time periods of either 30,60 or 90 minutes.

To examine the cultures microscopically, they were rinsed with Hank's BSS and either fixed with absolute methanol and stained with Giemsa's stain or fixed with buffered $3 \%$ glutaraldehyde, dehydrated, and stained with hematoxylin and eosin. Coverslips from Leighton tubes were mounted on glass slides.

\section{Sensitivity to Microcystin with Age in Rats and Mice}

Experiments using rats and mice of various ages were conducted to determine if juvenile and mature animals had the same or different sensitivities to microcystin. Two groups of 3 rats, each from the same litter, were challenged by $i . p$. injection with 1 MU of toxin. The first group weighed 20 grams, while the second group weighed 40 grams. Individual rats weighing 350 gms were given 3 MU or 10 MU, respectively. Symptoms and survival times were recorded and liver tissue was prepared for histological examination immediately after death or within 3 days for survivors.

Mice of different ages were given intraperitoneal injections of toxin equivalent to $1 \mathrm{MU}$ on a per weight basis. Animals chosen were: 1-2 days, 3-6 days, 12-15 days, and 20-24 days old and were from the same litter. The experiment was repeated 3 times using 3 
separate litters. Control animals were given equivalent amounts of non-toxic Microcystis aeruginosa extract. Symptoms and survival times were recorded and liver tissue was prepared for histological examination immediately after death or, in the case of survivors, within 3 days.

Sensitivity of Mice After Prior Exposure to Sublethal Doses of Micrecystis Toxin

Experiments were conducted to determine if previous exposure to sublethal doses of toxin might affect animal sensitivity to microcystin. Four groups of 4 mice (18 gm) were challenged, i.p., 3 times at 3 day intervals with the following: 1) $1.0 \mathrm{ml}$ nontoxic extract, 2) 0.1 MU of NRC-1 extract, 3) 0.2 MU of NRC-1 extract, and 4) $0.3 \mathrm{MU}$ NRC-1 extract. Three days after the last sublethal injection, all the mice ( $>20$ gm body wt.) in the group (toxin and control treated) were given 1 MU of NRC-1 extract. Symptoms and survival times were recorded, the livers were visually examined and then prepared for histological examination. In another experiment, 8 mice $(18 \mathrm{gm})$ were challenged with $0.3 \mathrm{MU}$ of NRC-1 extract 3 times over a 9 day period. Three days after the last injection, one animal was sacrificed and its liver was processed for histological examination, three animals were injected each with 1 MU of partially purified toxin, and 4 were given 1 MU of crude toxic extract. Symptoms and survival times were recorded and liver tissue was examined visually and then processed for histological examination. 
Measurement of Excitable Phenomena: Electro-Mechanical Studies

Electrophysiological and mechanical measurements on nerve and muscle tissues can be a valuable means of determining the site and mode of action of aquatic biotoxins. The following standard preparations were challenged with the toxin from Microcystis aeruginosa by direct bathing or injection: frog and mouse heart, frog sartorius muscles, frog sciatic nerves, and mouse ileum. Toxin samples for these tests were prepared as described above ( $1 \mathrm{MU} / \mathrm{m} 1$ ) and dissolved in the appropriate Ringer's solutions, i.e. Tyrodes for mice and amphibian Ringer's for frogs. Control preparations were run simultaneously and were bathed in, or injected with, nontoxic extracts of $\underline{M}$. aeruginosa. Striated, smooth and cardiac muscle contraction or tension development was monitored using FT-03C Force-Displacement Transducers and displayed on a Mode1 5

Polygraph (Grass Instrument Co., Quincy, Mass.). Action potentials in nerves were recorded externally using $\mathrm{Ag}-\mathrm{AgCl}$ electrodes and a Model 502A cathode ray oscilloscope (Tektronix Inc., Beaverton, Oregon) preceded by a Mode1 605 Electrometer (Keithley Instruments, Inc., Cleveland, Ohio). Frog and mouse electrocardiograms were recorded using needle electrodes, placed subcutaneously, and displayed on the Grass Polygraph.

\section{Toxicity Tests - Whole Organisms}

\section{Microorganisms}

Since microcystin's produced cyclic peptide structure may be similar to certain antibiotics, tests were designed to measure effects on the growth of microorganisms. The test organisms in- 
cluded gram negative and gram positive bacterial species, a fungus, and a green alga. Toxin samples were prepared in aqueous extract as previously described. Agar plates embedded with yeast (Saccharomyces cerevisiae) and Chlorella sp. received sterile filter discs soaked in either toxic or non-toxic extracts of Microcystis aerguinosa. Four discs (2 toxic; 2 non-toxic) were placed on each agar plate and growth was examined at 24,48 , and 72 hours. Other agar plates were prepared for general bacterial growth, and inoculated with Escherichia coli or Staphlococcus epidermidis, using sterile techniques. Four discs (2 toxic; 2 non-toxic) were placed on several plates containing each bacteria1 species. The plates were incubated at $37^{\circ} \mathrm{C}$ and examined every 12 hours for 3 days.

\section{Animal Assay}

Several aquatic animals, that might come in contact with toxic blooms of Microcystis aeruginosa in nature, were challenged with toxin, via immersion and intraperitoneal injection. Adult frogs and tadpoles (Rana pipiens, Rana catesbiena), crayfish (Cambarus sp.) fish (Carassius sp.), and cladocerans (Daphnia magna) were used in these assay experiments. The amphibians, crayfish and goldfish were injected, i.p., with 1 MU (or equivalent by wt.) ( $1 \mathrm{mg} / \mathrm{m} 1$ ) of NRC-1 extract that was toxic to mice. Control injections used non-toxic $\underline{M}$. aeruginosa samples. The animals were observed for up to 72 hours. In the immersion studies the test animals were exposed to toxin concentrations varying between 0.1 to $0.33 \mathrm{mg} / \mathrm{m} 1(0.1-0.33 \mathrm{MU} / \mathrm{m} 1)$ in volumes up to $30 \mathrm{mls}$. Lake 
water containing non-toxic $\underline{M}$. aeruginosa was used for control animals. All animals were observed for changes in mobility, response to tactile stimulation and general behavior, for several days. 


\section{RESULTS .}

The cyanobacterium, Microcystis aeruginosa, produces a unique biotoxin called microcystin (FDF) that is, apparently, very selective and specific with regard to the animal taxa that it effects. The results of the extensive assay tests performed in this study showed that selected bacteria, green algae, yeast, arthropods, amphibians, and teleosts were not affected by the Microcystis toxin in the concentrations used. In fact, field observations during extensive blooms of $\underline{M}$. aeruginosa in Kezar Lake showed the presence of several zooplankters (including Daphnia), amphibians, and small and large teleosts. The animals were commonly found in the densest bloom conditions, and the few dead fish observed could not be directly linked to the presence of M. aeruginosa. In the 1aboratory, neither the NRC-1 strain nor the control extracts produced any effects on the Chlorella, yeast or bacteria grown in culture under controlled conditions. There was no inhibition or augmentation of growth in any of the species of microorganism tested. Growth was uniform over the agar plates with no differences between the test, control or untreated areas of the cultures. Likewise, fish, amphibians, crayfish, and Daphnia magna were unaffected by the presence of toxin. None of the test organisms died or showed any symptoms of stress. Responses to tactile stimulation were similar in all respects to the controls.

The toxin did not alter the normal characteristics of the electrical and mechanical events associated with excitation phenomena in vertebrate nerve and muscle preparations. The experiments with 
smooth, skeletal, and cardiac muscle tissues did not reveal any differences between the control and toxin-treated preparations. In the presence of toxin, the smooth muscle contracted in long, slow, rhythmic waves, skeletal muscle produced contraction amplitudes or tension development equal to the controls for the duration of the experiment, and heart preparations showed no change in the electrical or mechanical aspects of the rhythmic beat sequence. Sciatic nerve action potentials were unaffected by the toxin as both toxin-treated and control preparations maintained the same action potential amplitudes and sensitivity to electrical stimuli after 90 minutes. The only major animal group affected by microcystin in this study was the mammals, specifically rats and mice. The NRC-1 strain of Microcystis aeruginosa from Canada and the strain from Kezar Lake were extremely toxic to mice. Using lyophilized crude extracts and partially purified samples, it was determined that 1.0 mg would reproducibly kill 20 gram animals in approximately 60 minutes. This is the equivalent of 1 mouse unit (MU) as described by Gorham (1962). The non-toxic extracts used for treatment of control animals did not kill mice or produce symptoms that indicated sublethal effects. Since mammals were the only animals affected by the toxin and the symptoms were not reminiscent of poisonings by other known cyanobacterial toxins, the problem became one of elucidating the site of action at the cellular/subcellular level in mammalian systems.

\section{Gross Observations of Toxin Treated Mice}

After i.p. injection, the mice were agitated and breathed 
rapidly, but they calmed down within minutes and displayed normal behavior. After approximately 15 minutes, the animals became somewhat lethargic. At the end of 30 minutes, they were even less responsive to stimuli, showed some difficulty in moving and the ears, tips of tails, and the ends of their extremities appeared paler. After 45 minutes, mobility was difficult, breathing was labored, and the animals remained on their bellies with their limbs extended. After approximately 60 minutes, the animals could no longer move, except to turn themselves over when placed on their backs. They were not responsive to touch, noise, etc., and the ears and limbs had become white. Breathing was deep and labored and ceased in approximately one hour; death ensued without convulsions.

The mice were immediately dissected open to reveal a greatly enlarged, dark red liver with a mottled surface. The blotches on the surface appeared as numerous, small, red, "spiderlike" areas surrounded by abnormally paler tissue. The edges of the liver were more rounded and when the liver was incised, it often bled profusely, the blood being a very dark red. During the time course study, it was noted that the liver began to swell and become a darker red color 15 to 20 minutes after injection.

All other organs appeared normal (as in the controls). The heart was often beating arrhythmically, sometimes with auricular flutter and always with arrhythmic or spasmodic ventricular contractions. This arrhythmia was noted after either cervical dislocation or when dissecting open a fatally poisoned animal. No in vitro effects were observed in mouse hearts. These results were the same for both the NRC-1 strain and the Kezar Lake Microcystis extracts. The same results were obtained whether crude or partially 
purified extracts were used.

\section{Liver Weight and Volume}

The results of the mouse liver weight and volume studies are summarized in Table 2. Using the $F$ test for significance, there was no statistically significant difference at either the 95 or $99 \%$ confidence intervals between the weights of the control and experimental mice. Again using the F test, the weights of control and experimental livers showed highly significant differences at the 95 and $99 \%$ confidence intervals. It is obvious from gross observations and these measurements, that the livers accumulated a large amount of blood.

Histological Observations 60 Minutes (Figures $4 \mathrm{E}$ and $4 \mathrm{~F}$, Figures $5 G$ and $5 H$ )

There were no significant lesions or histological differences between control and experimental mice in any organs but the liver. After dying in approximately 60 minutes from the administration of toxin ( $1 \mathrm{MU})$, the liver tissue showed extensive congestion and hemorrhage. Although these changes were diffuse, they appeared more intense in the centrilobular regions (areas around the central veins). Hepatocytes were rounded and swollen with a "ground glass" appearance to their cytoplasm. Intense cytoplasmic eosinophilia suggested early death of hepatocytes. In many centrilobular areas whole cells could no longer be distinguished while there appeared to be a great deal of amorphous material present (most likely cell debris). Parenchymal cord structure was destroyed and isolated 
TABLE 2

LIVER WEIGHT AND VOLUME MEASUREMENTS

CONTROLS

Mouse Wt. Liver Wt. \%
(g)
(g)
(1iver:body)

1. 17.90

2. 15.00

3. 20.23

4. 23.28

5. 22.12

6. 21.07

7. 23.20

8. 24.06

0.95

0.69

0.85

1.24

1.39

1.41

1.25

1.14

9. 21.75

1.16

10. 21.50

1.05

11. 21.26

1.00

12. 20.53

0.98

0.85

13. 19.90

14. 20.20

1.03

0.73

$\begin{array}{lll}\mathrm{T}=309.93 & \mathrm{~T}=15.70 & \mathrm{~T}=75.3 \\ \overline{\mathrm{X}}=20.66 & \overline{\mathrm{X}}=1.05 & \overline{\mathrm{X}}=5.02\end{array}$

5.3

4.6

4.2

5.3

6.3

6.7

5.4

4.7

5.0

4.9

4.7

4.7

4.3

5.1

4.1

$\overline{\mathrm{X}}=5.02$
Liver Vol.

(cc)

0.80

0.50

0.70

1.00

1.30

1.20

1.00

1.00

1.10

0.90

0.50

0.90

0.60

0.90

0.50

$\mathrm{T}=12.9$

$\overline{\mathrm{X}}=0.86$

\section{EXPERIMENTALS}

Liver Vol.
(g)
(g) (liver:body) (cc)

ver Wt. \%

$\begin{array}{llll}20.25 & 1.73 & 8.5 & 1.60 \\ 19.32 & 1.04 & 5.4 & 1.00 \\ 20.23 & 2.02 & 9.9 & 2.00 \\ 17.72 & 1.18 & 6.6 & 1.20 \\ 21.04 & 1.97 & 9.4 & 1.90 \\ 16.78 & 1.28 & 7.6 & 1.40 \\ 17.73 & 1.41 & 7.9 & 1.25 \\ 18.04 & 1.38 & 7.7 & 1.44 \\ 18.02 & 0.82 & 4.5 & 1.00 \\ 20.27 & 1.65 & 8.1 & 1.70 \\ 23.65 & 1.95 & 8.2 & 1.70 \\ 20.06 & 1.55 & 7.8 & 1.50 \\ 17.14 & 1.46 & 8.5 & 1.40 \\ 18.54 & 1.66 & 8.9 & 1.50 \\ 20.34 & 1.55 & 7.6 & 1.50\end{array}$

.60

20

90

.40

.25

1.44

1.00

1.70

1.70

1.50

.50

$\mathrm{T}=22.09$

$\overline{\mathrm{X}}=1.47$ 
hepatocytes were present, most with rough, irregular and poorly defined cell boundaries. Nuclear changes were minimal although isolated nuclei were often observed, especially in the centrilobular regions immediately around the central veins. All of the damage was most pronounced in the inner centrilobular areas. Sinusoids were no longer discernable in the centrilobular areas and were swollen in areas further from the central veins. Sinusoidal spaces were engorged with RBC's and cell debris. Endothelial tissue of the sinusoids was swollen, rough or poorly defined, or absent. Amorphous material could often be seen on the luminal surface of the sinusoidal endothelium. The endothelium of hepatic arterioles, venules, and bile ducts did not appear to be involved. Larger blood vessels usually contained many RBC's but little amorphous material.

Where hemorrhage was less intense, the hepatocytes often had a vacuolated appearance.

The overall damage was characterized by extensive hemorrhage and the centrilobular pattern of tissue involvement.

\section{Minutes (Figures $5 \mathrm{E}$ and $5 \mathrm{~F}$ )}

The hemorrhage appeared less extensive but was still acute in the centrilobular and subcapsular areas. Sinusoids were swollen but more parenchymal cord structure could be observed, although destruction of this organization was present around the central veins. Less amorphous material was present, cells were more distinct but greatly swollen. There was decreased eosinophilia especially toward the periphery of the lobules. Isolated hepatocytes 
and hepatocyte nuclei could still be found, even in the large blood vessels and vacuolization of hepatocytes was also observed. There was the same type of damage as at 60 minutes but to a decreased extent. Again, much blood had accumulated in the liver.

20 Minutes (Figure $5 \mathrm{C}$ and $5 \mathrm{D}$ )

At this time, there was much less hemorrhage than at 60 minutes and thus many fewer RBC's. Sinusoids, especially in the centrilobular area, were dilated and contained numerous RBC's. There was also hemorrhaging in the subcapsular area with many RBC's packed into this space.

Parenchymal cord structure was more apparent but hepatocytes were still swollen, especially in the centrilobular region. Fewer areas were involved, the damage was less diffuse, and endothelial tissue appeared more normal (as in controls).

\section{Minutes (Figures $5 \mathrm{~A}$ and $5 \mathrm{~B}$ )}

The liver at this time was more like that of the controls. There was some localized subcapsular hemorrhaging, few centrilobular areas showed signs of damage, and endothelial involvement was minimal.

There was no significant differences between the untreated controls and those given extracts of non-toxic Microcystis aeruginosa.

\section{Partially Purified Extracts}

Histological studies with partially purified microcystin gave results identical to those above. The supernatants from centri- 
fuged extracts were passed through a 100,000 dalton molecular separation membrane to yield a clear, colorless, toxic filtrate; this was then passed through a 10,000 dalton membrane and toxicity was again confirmed. Molecules smaller than 500 daltons were removed from the toxin solution using another membrane and the retentate was concentrated by evaporation. The toxicity of all aliquots was tested in mice (i.p.). Samples of liver were removed and prepared for histological examination. Death times were approximately 60 minutes and the location, extent, and type of damage were all identical to the damage produced by crude extracts of both NRC-1 and Kezar Lake strains.

\section{U1trastructural Effects}

The following are descriptions of the cellular/subcellular effects of a fatal dose ( $1 \mathrm{MU}$ ) of microcystin (FDF) on mouse liver tissue. The effects are noted after 10, 20, 40, and 60 minute exposures to the toxin. Figure 7 is a reference illustration of mouse hepatic tissue organization and Figure 8 is of a typical mouse hepatocyte.

\section{Untreated Controls (Figure 7)}

The livers from healthy, untreated mice did not show any distortion of normal hepatic structure. At lower transmission electron microscope (TEM) magnifications, cells can be seen to be joined in normal hepatic parenchymal cord structure, bile canaliculi are present with microvilli, endothelial tissue in the sinusoids (including Kupfer cells) appears normal and endocytic processes were observed. The spaces of Disse did not appear distorted and the hepatocyte sur- 
faces exposed to these spaces were covered with numerous microvilli. Although RBC's and leukocytes were present in blood vessels they were infrequently observed in sinusoids, and even in blood vessels the number of blood cells was low (probably due to washing, fixation, and dehydration procedures).

Hepatocytes showed normal cell morphology with no observable distortions of cell shape, size or surface morphology (Figure 9). All cell organelles and inclusions appeared normal. There was a large amount of glycogen and rough endoplasmic reticulum (RER) present with adjacent mitochondria. Many mitochondria appeared to be closely associated with the RER and were actually surrounded by it. Glycogen rosettes stained heavily and could be found concentrated in large areas of cytoplasm, almost to the exclusion of other organelles or inclusions. The RER was not swollen; its membranes were arrayed in parallel and the cisternae did not contain densely staining material. The outer surfaces of RER membranes were studded with ribosomes. RER was also found concentrated in large areas of cytoplasm adjacent to, but separate from, areas of glycogen storage. There were few lysosomes and these usually appeared in the peribiliary areas. Few lipid droplets were noted which were not usually associated with mitochondria. Nuclearnucleolar morphology was also normal. Smooth endoplasmic reticulum (SER) was not prominant, myelenoid bodies were not present, Golgi bodies were only rarely observed and there was no vesiculation in the cytoplasm. 


\section{Treated Controls (Figure 8)}

In the mice given non-toxic Microcystis aeruginosa extracts, all hepatic tissue structure appeared normal and similar to untreated controls. Hepatocytes showed normal morphology as in the untreated controls and organelles and inclusions appeared norma1 except for mitochondria which were swollen in some cells. In these cells, a number of swollen mitochondria had distended portions of both inner and outer membranes. This "ballooning out" left large, clear areas in the mitochondrial matrix (Figure $8 \mathrm{E}$ and F). There was no intracristal swelling and no distension of the intermembrane space.

No ce11 lysis or hemorrhaging was ever observed.

\section{Toxin Treated Liver - 60 Minutes (Figures 9-12)}

In these tissues, the cell degeneration and necrosis visable in histological preparations was seen as extensive cell disruption and disaggregation. In the centrilobular areas especiaily, the parenchymal cord structure was missing as cells had rounded up and pulled apart or were 1ysed. Sinusoids were enlarged and endothelial tissue in these areas was either swollen, lysed, or completely missing. Bile canaliculi were either greatly compressed between swollen hepatocytes or were greatly distended. Microvilli in the canaliculi were fewer and larger between the swollen cells and either distended or absent in cells that were detaching from each other. The microvilli in the spaces of Disse were also either swollen and distorted or were reduced to slight swellings on the hepatocyte surface. Damage to the lobular structure in general and hepatocytes in 
particular, was most intense in the centrilobular areas (those areas surrounding the central veins) and became progressively less intense toward the periphery where there were intact cells. Peripheral cells were swollen, of ten contained irregular shaped vacuoles (open, membrane-bound areas of lesser density), as well as swollen mitochondria, some of which showed "ballooning" of the outer membranes. Cell swelling, distortion, and the number of lysed cells increased toward the central veins where all cells were destroyed and massive hemorrhaging occurred. The intercellular spaces (formerly sinusoids) were filled with RBC's and cell debris.

Lysed cells showed either discontinuities in the plasma membrane or no membrane was visible. Organelles and inclusions were spilled out of the cell and pooled with RBC's. There did not appear to be any gross alteration of these free organelles and inclusions. Mitochondria were round and swollen but the density of their matrix appeared as in the controls; there was no intermembrane swelling, and no change in the morphology of cristae. The RER was fragmented but there was no swelling of cisternae, no densely staining material or abnormally clear spaces in the cisternae, and numerous ribosomes were still attached to the outer surface of the parallel membranes. Isolated nuclei were frequently observed and contained morphologically unchanged hetero- and euchromatin and nucleoli. In some nuclei, the outer surfaces were convoluted, but still had a double outer membrane with ribosomes attached to the outer membrane that interfaced with the cytoplasm. Membrane fragments were of ten seen, many of which had vesiculated; glycogen appeared unchanged as free beta particles that spilled from the cell. In some sections lipid bodies were observed. 
In intact hepatocytes located at the periphery of lobules, distortions appeared as in the centrilobular regions, only at shorter times after toxin injection. Cells were swollen, surface characteristics were abnormal, cells did not appear firmly attached to one another, and endothelial cells were either swollen or only membrane fragments were seen.

\section{Minutes NRC-1 (Figures 13 and 14)}

At this time, the damage to the liver was the same as at 60 minutes except that it was less extensive. Sinusoids, where present and not fragmented, were swollen; many RBC's were present; spaces of Disse, bile canaliculi, and microvilli were either absent in centrilobular areas or greatly distorted in surrounding regions; endothelial tissue was missing, fragmented or swollen depending on its location in the lobule. Cell disruption had taken place in centrilobular areas and there was much pooling of RBC's and cell organelles and inclusions. The free cell structures were not grossly changed except for mitochondrial swelling, nuclear convolution and fragmentation of RER. Fewer hepatocytes were lysed but membrane discontinuities were seen in those cells that were in the process of breaking apart.

\section{Minutes NRC-1 (Figure 15)}

Hepatocytes were intact and much more like the control sections. There were many fewer swollen mitochondria, bile canaliculi and microvilli in the spaces of Disse appeared less distorted, and organelles and inclusions (other than mitochondria) had normal 
morphology. Endothelial tissue was either fragmented, as many membrane fragments and myelinoid-like bodies were seen, or it was swollen.

10 Minutes NRC-1 (Figure 16)

All cells appeared as in controls with some mitochondrial swelling. The one notable difference was the presence of membrane fragments in the sinusoids. Many of these fragments were rounded up or appeared vesiculated.

\section{Ce11 Culture Experiments - Isolated Hepatocytes}

Although dense, healthy monlayers of rat and mouse hepatocytes could not be achieved, many cells did attach to the glass slides of the Leighten tubes and were tested for sensitivity to the toxin.

Best results were obtained when 10 to $20 \%$ fetal calf serum was added to the medium and the medium was changed within several hours after cell disagregation. Collagenase (0.05\%) was less harmful to the cells, gave greater viability, and large cell yields. MAB $87 / 3$ appeared to be the most efficient medium. Seedings of 1 to $2 \times 10^{6}$ gave more attached cells than the lower concentrations. Rat liver tissue gave better cell attachment with healthier cells than the mouse liver. There was no evidence of bacterial or fungal contaminants. Primary cultures containing microexplants were often the most successful cultures.

The results of all experiments with either mouse or rat primary hepatocyte cultures were identical. All hepatocytes in culture appeared to be more vacuolated and pointed (less polygonal) than 
would be expected of healthy epithelioid cells. These characteristics were also observed in microexplants of from five to fifteen cells, but to a much lesser extent. Cells in layers were flattened from attachment, had large nuclei, visible nucleoli and readily observed cytoplasmic inclusions.

All controls, whether treated with fresh medium only or with non-toxic Microcystis aeruginosa extract appeared identical.

The experimental primary cultures treated with toxic extracts, for varying periods of time did not differ in any noticeable aspects, either from each other or from the controls. The only difference observed was a decreased number of attached hepatocytes as the time of exposure to the toxic solution increased. This was noted in the controls but to a lesser degree. Cell morphology did not change in the attached cells.

Greater viability and healthier cells in the microexplants led to the use of these cells in place of monolayers. Toxin did not appear to affect the neonatal or juvenile hepatocytes in either layers or microexplants in vitro (Figure 17).

\section{Sensitivity with Age}

Newborn and very young mice were not killed by the i.p. injection of the equivalent (on a mouse weight basis) of $1 \mathrm{MU}$ of toxic Microcystis (NRC-1) extract. Neither newborn mice nor mice of approximately 5 or 10 days of age showed any symptoms of poisoning, gross liver changes or histological liver lesions. Mice approximately 20 days old were killed by the equivalent of $I$ MU of toxin but in all cases the survival times were longer than expected for this dose level. 
The survival times were closer to 2 hours. These fatally poisoned animals showed symptoms of microcystin poisoning, had swollen and darkened livers, and their livers contained centrilobular lesions identical to those previously described in mice that had been injected with this toxin. 
Figure 1.

Kezar Lake, North Sutton, New Hampshire. October, 1978. A massive bloom of toxic Microcystis aeruginosa was in progress and had turned the entire lake green.

Figure 2.

A colony of toxic $\underline{M}$. aeruginosa cells as seen with bright field microscopy (400x). 


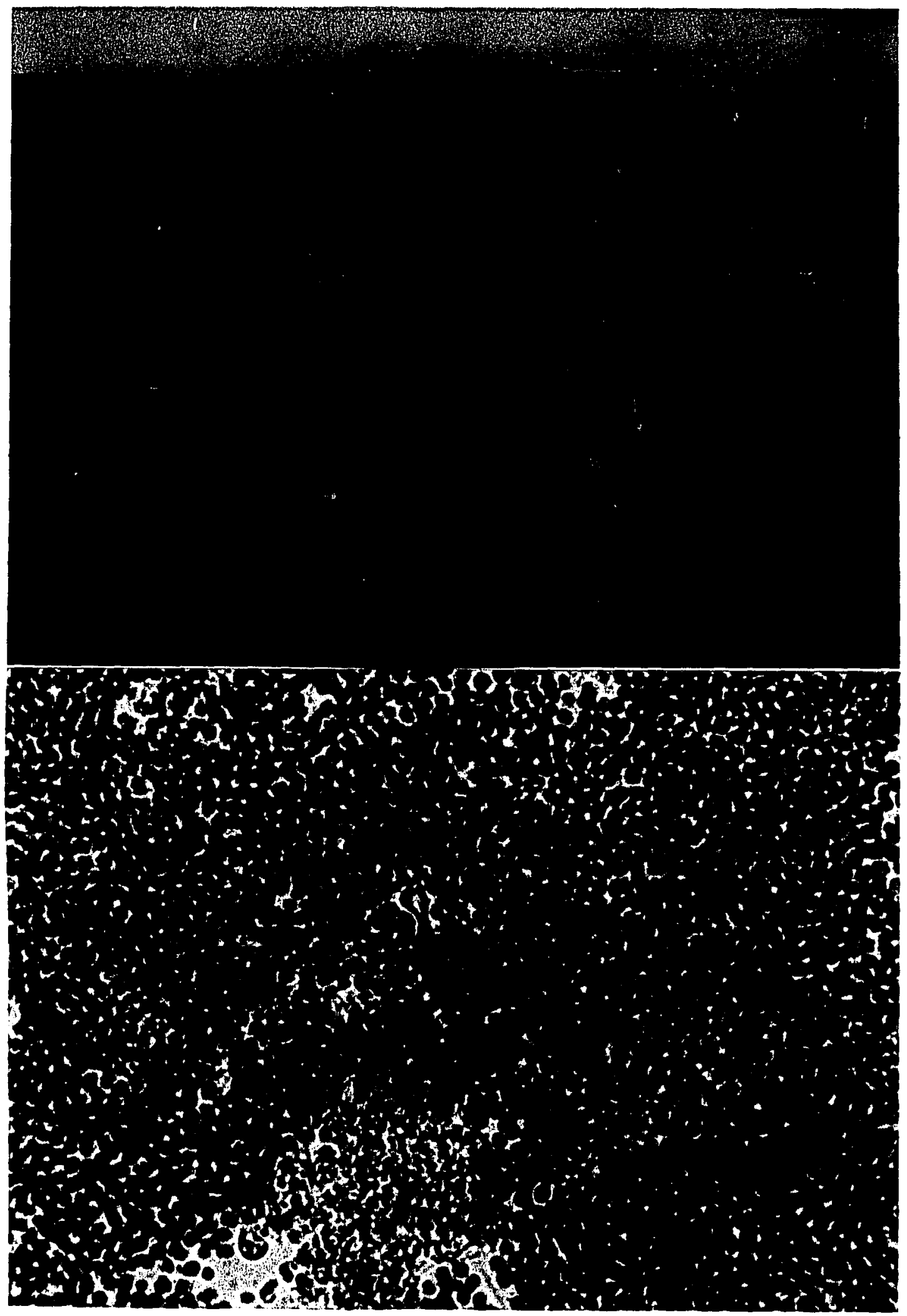


Figure 3.

(A) A colony of toxic Microcystis aeruginosa cells in a gelatinous mass $(1200 \mathrm{X})$, (B) toxic M. aeruginosa cells showing the presence of rod shaped bacteria living within the gelatinous mass with the cyanobacterium (3500X), (C) a higher magnification of two single cells anchored to the gelatinous mass with filaments but not covered by it in this preparation (4500X), (D) a pair of toxic cells from which the sheath material is missing (7200X). 

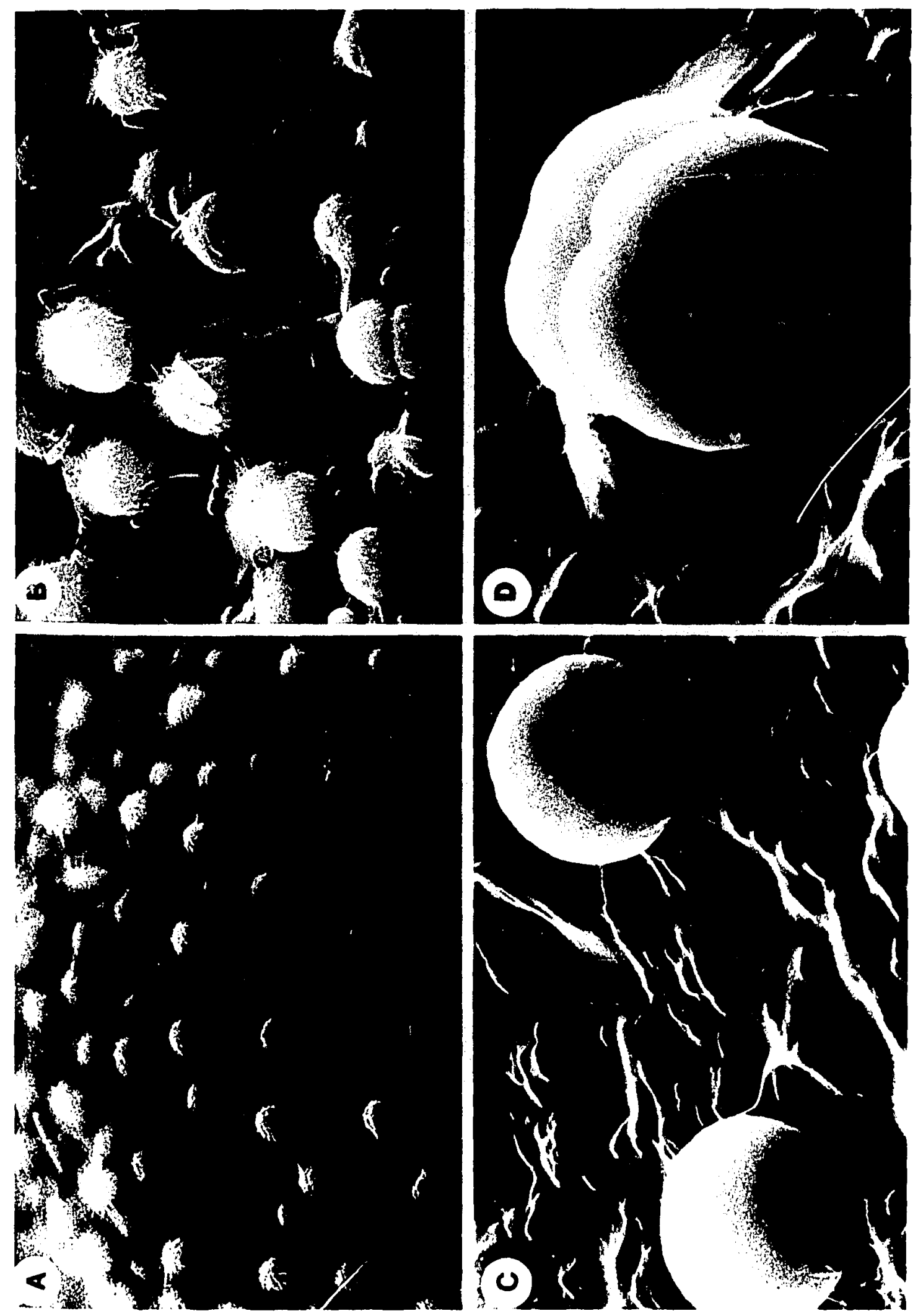
Figure 4.

Histological preparations of mouse liver. All show central veins in the center of hepatic lobules. (A) untreated control $(100 \mathrm{x})$, (B) untreated contro1 (400X), (C) control exposed to a non-toxic extract of $\underline{M}$. aeruginosa (100X), (D) same as (C) (400X), (E) liver exposed to a fatal dose of toxic extract from $M$. aeruginosa collected from Kezar Lake, NH (100X), (F) same as (E) (400X). The last two show disintegration of parenchymal cord structure, numerous erythrocytes, swollen hepatocytes, and the centrilobular nature of hepatic damage. All sections are stained with hematoxylin and eosin. 


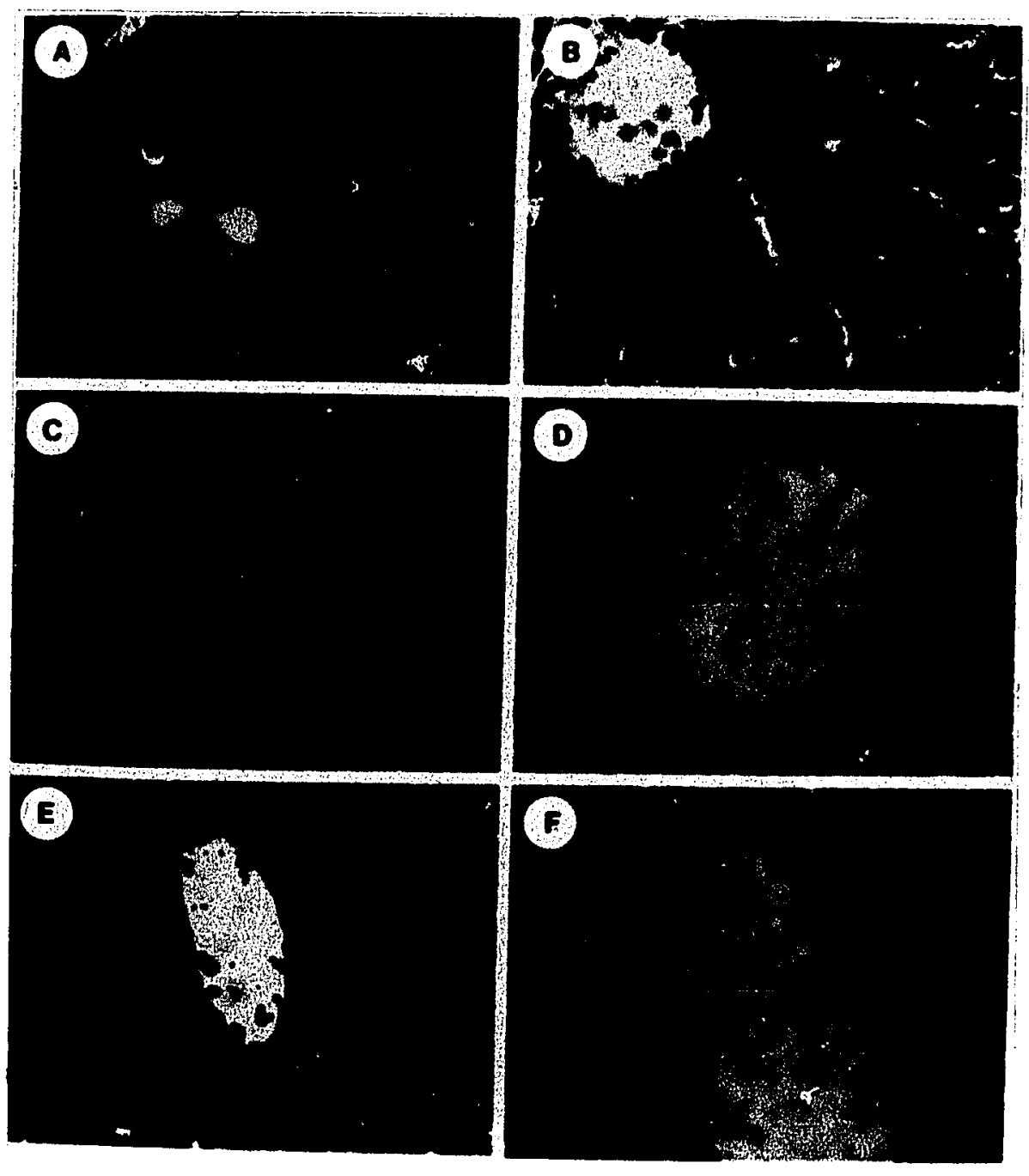




\section{Figure 5.}

Histological preparations of mouse liver treated with toxic extracts from the NRC-1 strain of $M$. aeruginosa for 10 minutes (A) and (B), 20 minutes (C) and (D), 40 minutes $(E)$ and $(F)$, and 60 minutes $(G)$ and $(H)$. All preparations in the left colum are $100 \mathrm{X}$ and those in the right column are 400X. All sections show central veins and the centrilobular nature of the damage.

Note the cell swelling, intercellular $\mathrm{RBC}^{\prime} \mathrm{s}$, loss of tissue structure, and cytoplasmic changes. 


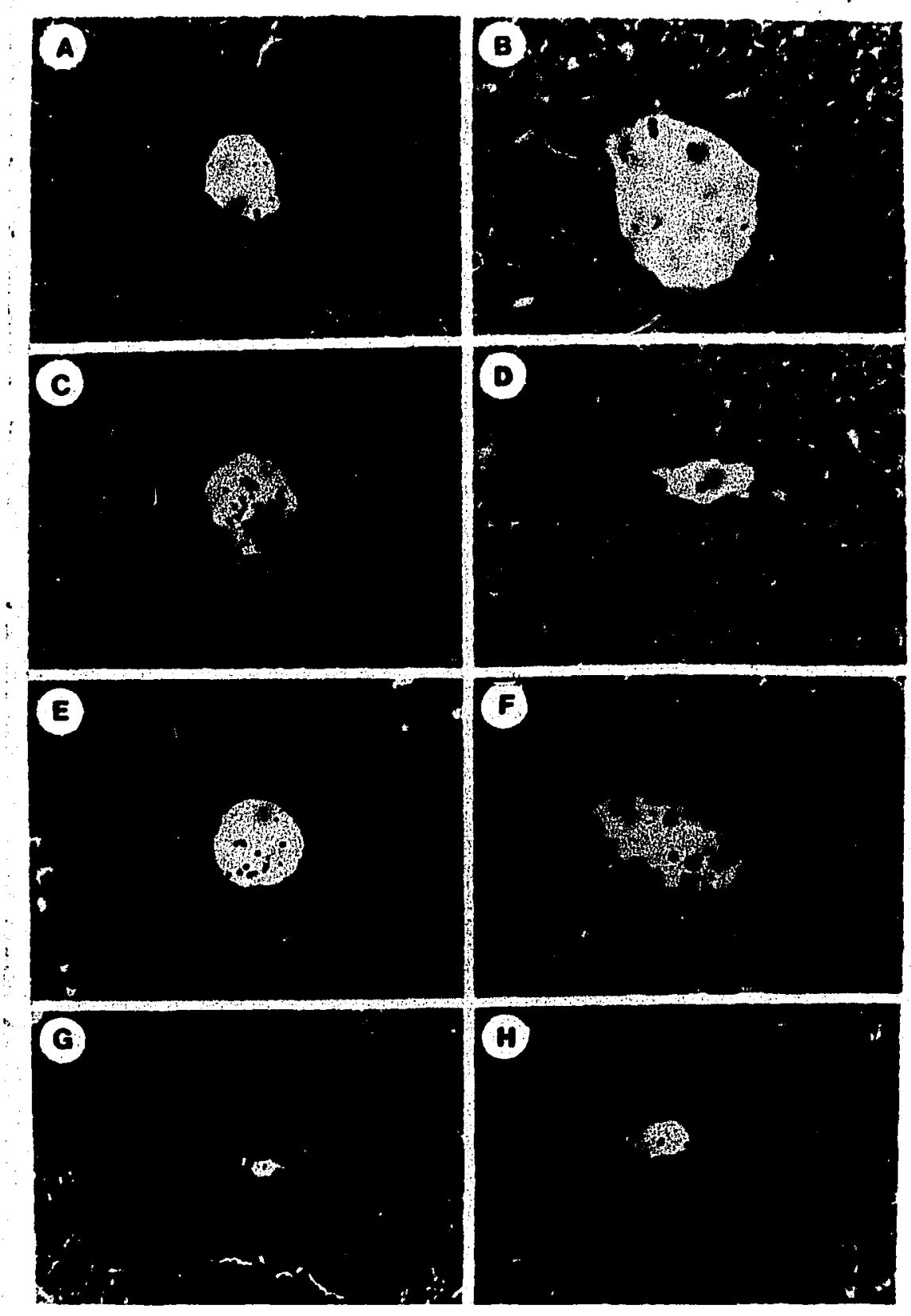




\section{Figure 6.}

Diagrams illustrating the areas of mouse liver examined histologically and ultrastructurally.

(A) A section through a liver lobule showing the central vein (CV), bile duct (BD), hepatic artery (HA), and interlobular vein (IV). See lower left hand corner of diagram.

(B) A section of the lobule showing the central vein (CV), red blood cells (RBC), sinusoids (SIN), endothelium (ENDO), bile canaliculus $(B C)$, bile duct $(B D)$, hepatocytes $(H)$, hepatic artery (HA), liver vein (LV), interlobular vein (IV). The thick arrow in the sinusoid indicates the direction of blood flow and the thin arrow in the bile duct indicates the direction of bile flow.

(c) This diagram is an illustration of one hepatocyte and portions of surrounding sinusoids with their endothelial lining. Note that the endothelium does not form an impermeable barrier between the blood and the hepatocyte but has large fenestrations in it. Some of the cellular components are labelled.

Erythrocytes (RBC), sinusoids (SIN), endothelium (ENDO), space of Disse (SD), microvilli (MV), bile canaliculus (BC), nucleus (N), nucleolus (NU), rough endoplasmic reticulum (RER), mitochondria (M), golgi (G), and lysosomes (LYS). 


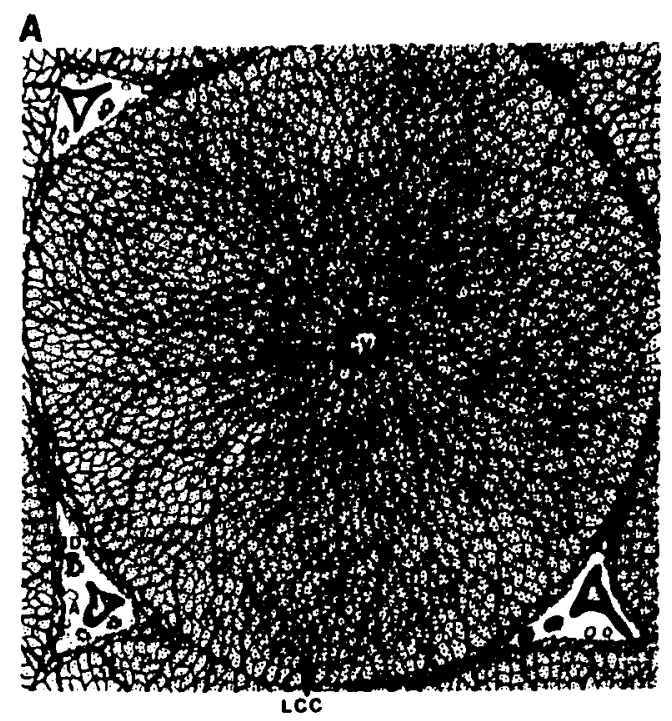

B

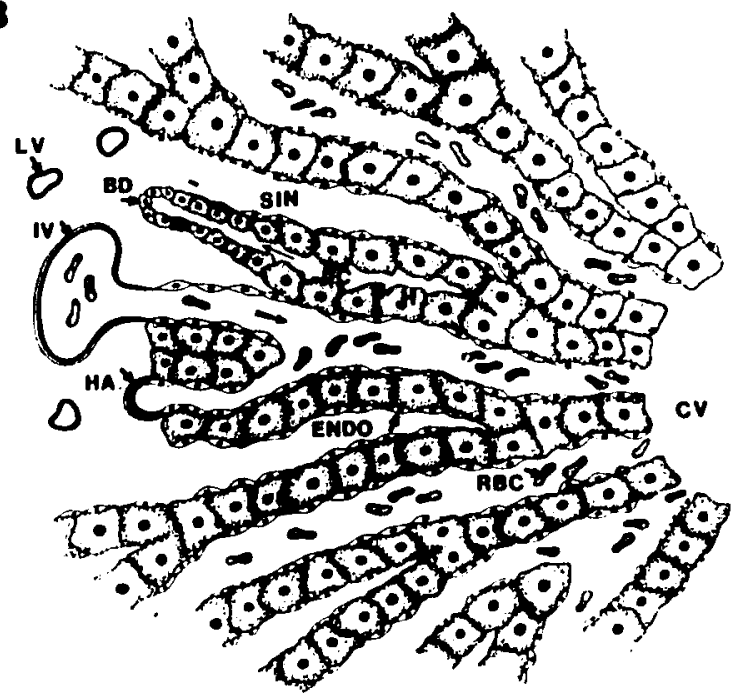

C

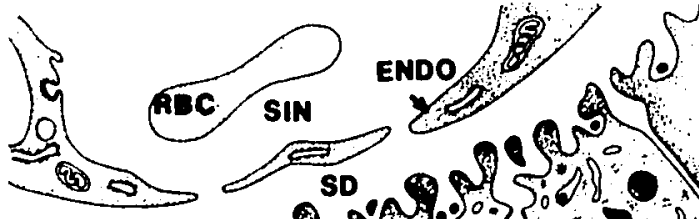

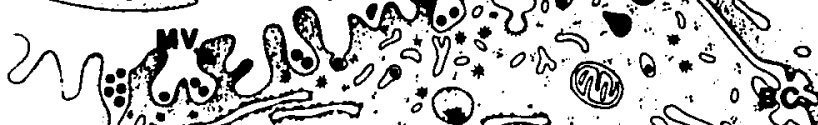

$\sqrt{3}$

(ivi 0 on

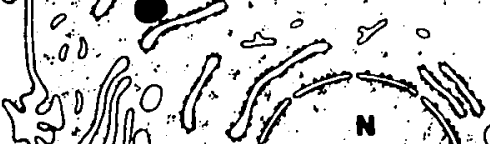

ros

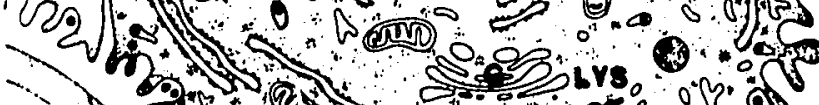

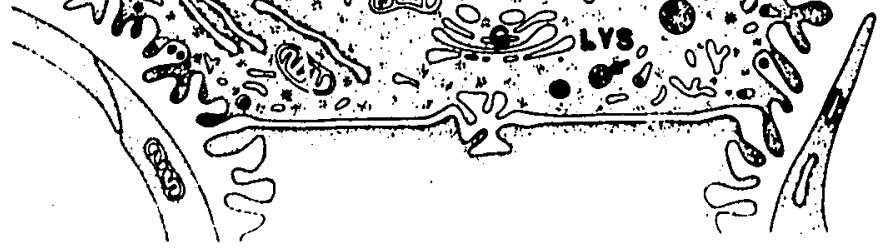




\section{Figure 7.}

Untreated control mouse liver cells.

(A) Part of a single hepatocyte showing the normal components of such cells. Note the pools of glycogen (GLY), the numerous mitochondria (M) and areas containing large amounts of lamellar rough endoplasmic reticulum (RER) with normally attached ribosomes. Lipid droplets (L) are present and one bile canaliculus (BC) is in view. The nucleus (N) shows normal morphology and arrangement of euchromatin, heterochromatin and nucleolus (6000X). (B) A section showing a sinusoid (SIN) with its endothelial lining on top of hepatocytic microvilli (7500X). (C) A higher magnification showing the surface detail of one hepatocyte $(H)$ with its surface microvilli (MV). Endothelium (ENDO) forms the lining of the sinusoids (14000X). 

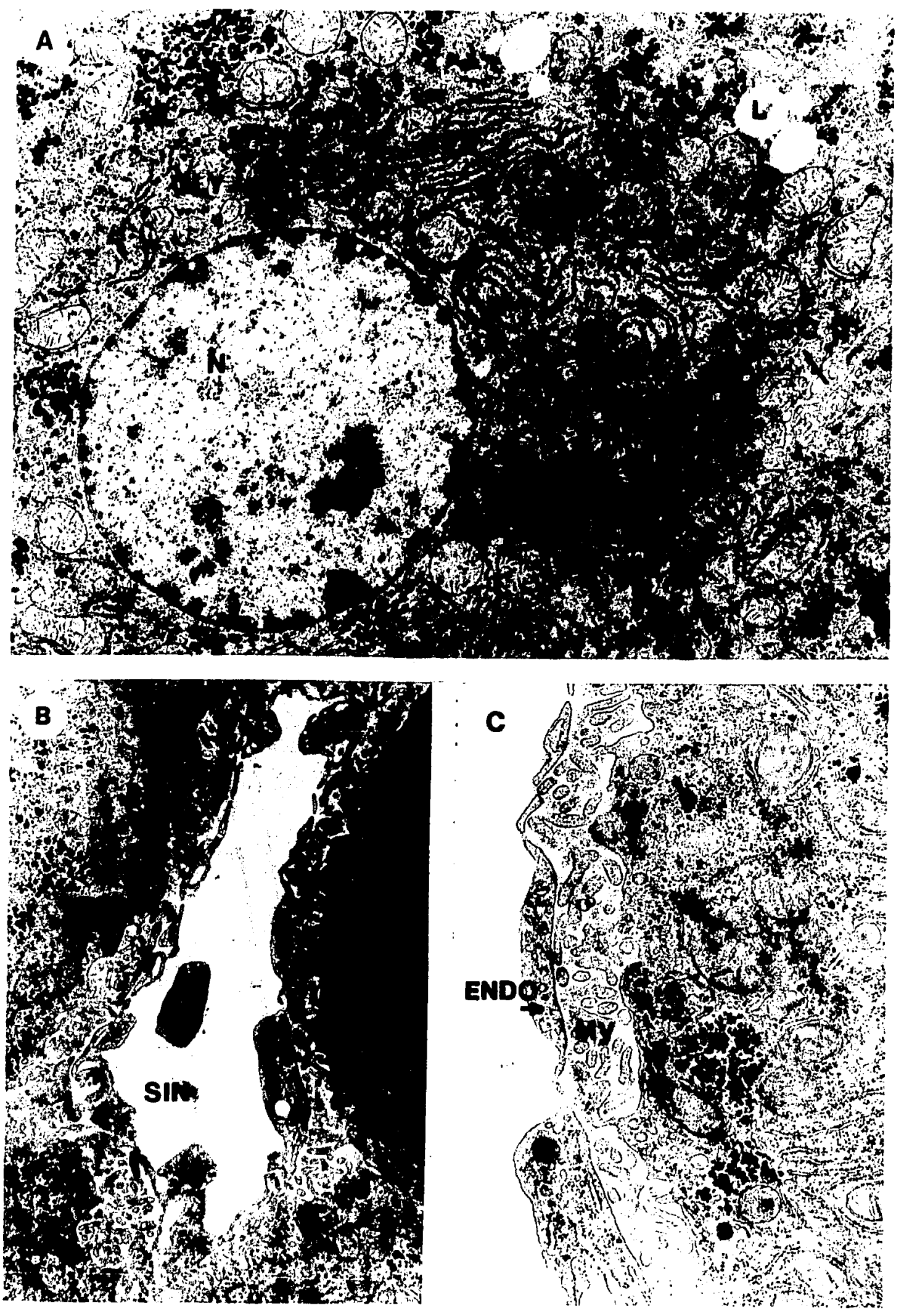
Figure 8 .

Mouse liver cells treated with extracts of non-toxic $\underline{M}$. aeruginosa for 60 minutes.

(A) A hepatocyte nucleus with normal morphology; cytoplasm contains pools of glycogen and areas with a large amount of rough endoplasmic reticulum (RER) (4000X). (B) A higher magnification of the cytoplasm showing normal organelles and inclusions $(6000 \mathrm{X})$. (C) A sinusoid containing a single RBC (4000X). (D) A high magnification of a sinusoid showing the endothelial lining with its openings to the space of Disse below. Note the numerous, slender microvilli on the surface of a portion of a hepatocyte (12500X). (E) Cytoplasm of a hepatocyte with swollen mitochondria. In the upper right is a bile canaliculus (4000X). (F) A higher magnification of the swollen mitochondria seen in $(E)(6000 \mathrm{X})$. This phenomena was not observed in either untreated controls or poisoned mouse hepatocytes. 

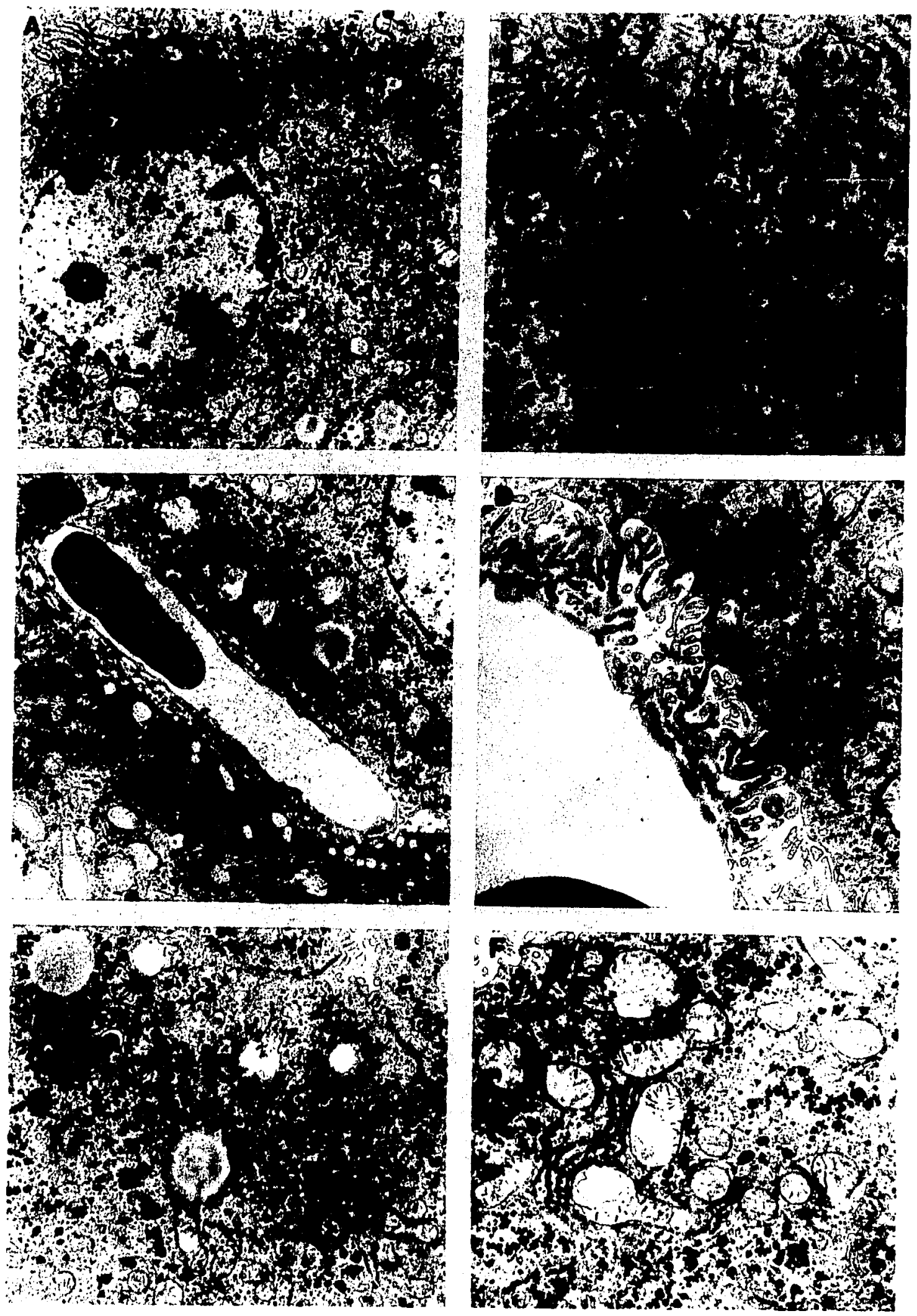


\section{Figure 9.}

Mouse liver exposed to toxic NRC-1 extract for 60 minutes. (A) In this acutely poisoned liver there is a swollen, rounded, smooth-surfaced hepatocyte (upper right) containing swollen mitochondria in association with RER and although the cytoplasm appears washed out, numerous small vesicles are seen. This cell appears to be on the verge of rupturing (5000X). (B) This micrograph shows a single hepatocyte nucleus (lower center) surrounded by cell organelles and RBC's. No cellular organization remains as the hepatocyte has lysed and its contents have mixed with blood (4000X).

These two electron micrographs illustrate the nature of the centrilobular destruction seen in toxin poisoned mammals. 

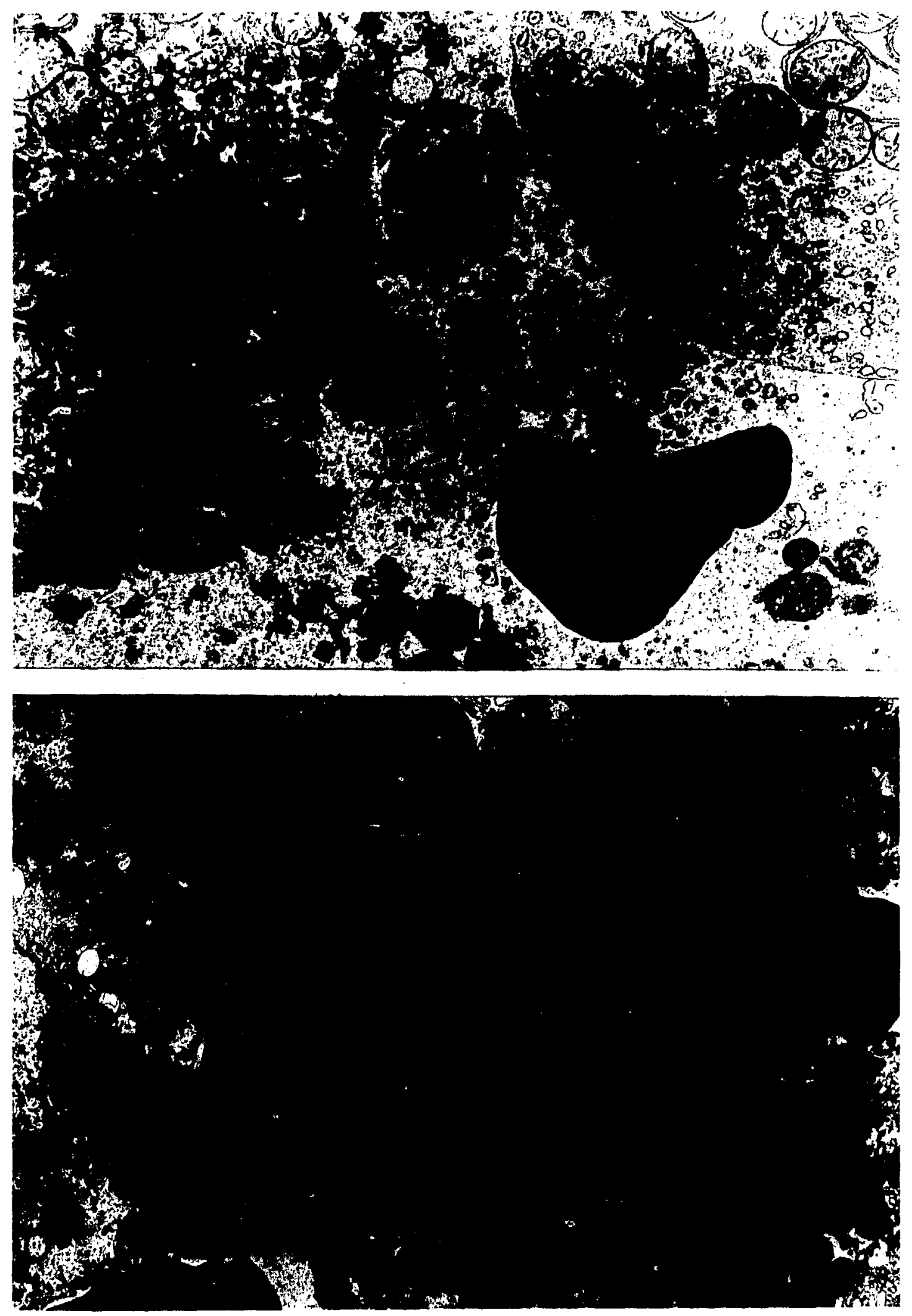
Figure 10.

Mouse liver exposed to toxic NRC-1 extracts for 60 minutes. (A) Upper right and lower left show parts of hepatocytes. Note intact organelles. In the center is a sinusoid containing RBC's and lined with distended endothelium that contains rather sparse cytoplasm. The spaces of Disse are compressed and few microvilli are present; those few are very distorted (4500X). (B) Similar to (A) and illustrating the degeneration of endothelium (5900X). (C) Portions of the surfaces of two hepatocytes showing surface destruction, absence of microvilli, vesiculated membranes and what appear to be discontinuous areas in the plasma membrane $(8900 \mathrm{X})$. (D) Distorted hepatocytes pulled away from each other $(5900 \mathrm{x})$. 

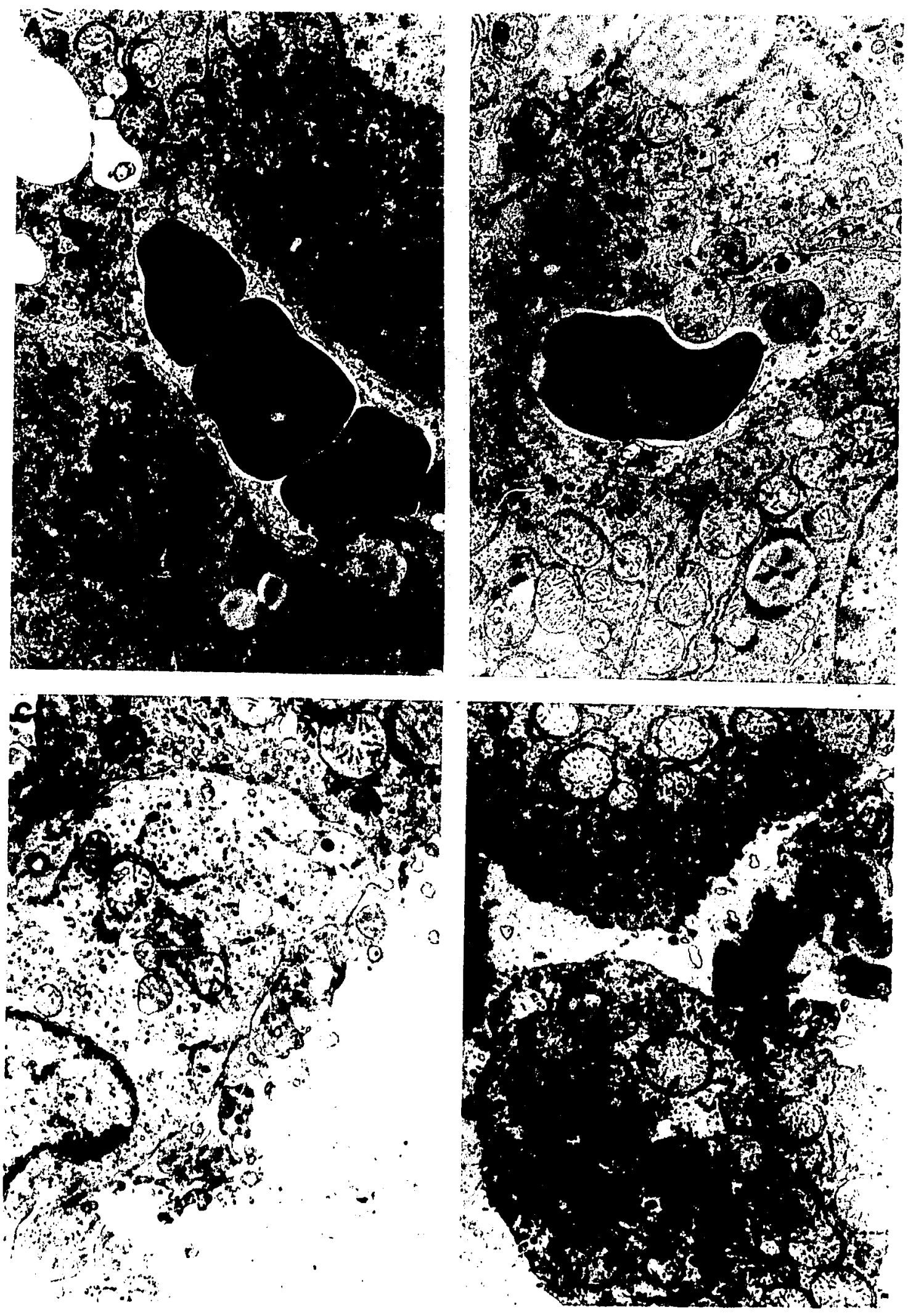
Figure 11.

Mouse liver acutely poisoned (60 minutes) by toxin extracts of $\mathrm{M}$. aeruginosa from Kezar Lake, $\mathrm{NH}$.

(A) A sinusoid containing a granular, amorphous material and lined by a swollen, "ghost-like" endothelial cell in which a few organelles can still be distinguished. Hepatocytes surrounding the sinusoid appear swollen and are becoming detached, microvilli are fewer and compressed into a distorted space of Disse (5000X). (B) The lower right shows a swollen hepatocyte containing several mitochondria, some RER, and a lysosome but lacking normal cytoplasmic appearance. The surface of this cell is absent of microvilli and in the space between the cell and the adjacent Kupfer cell (large nucelus in the upper middle) there appears to be much cell debris. Several RBC's are visible in the lower portion of this micrograph (5000X). (C) Remnants of endothelium line this sinusoid containing several membranous vesicles. Surrounding hepatocytes have greatly distorted surfaces lacking microvilli. A lipid droplet is seen in the upper left and several swollen mitochondria are observed in association with RER (6000X). (D) A high magnification of a RBC (right) and a portion of a hepatocyte (upper left) with the remnants of microvilli on its surface. Note the large myelin figure (dark circular object) composed of lamellar rings of membrane fragments. Also, note the long, interrupted membrane next to the RBC. The endothelial lining is gone and normal cellular organization in the space of Disse is absent. The plasma membrane does not appear to be completely continuous $(20,000 \mathrm{X})$. 

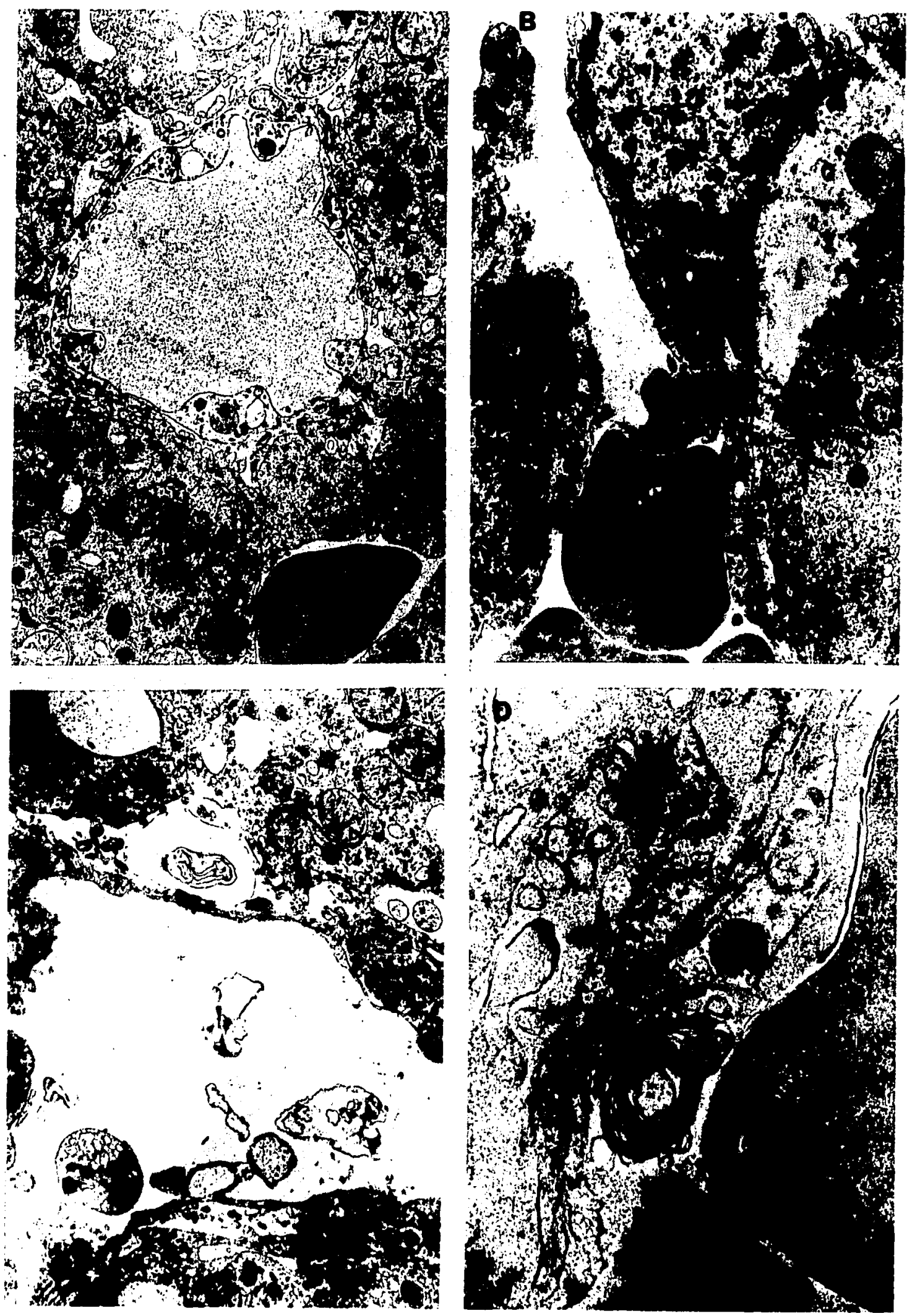
Figure 12.

Mouse liver acutely poisoned (60 minutes) by toxic extracts of $M$. aeruginosa from Kezar Lake, NH.

(A) Upper and lower left of center are two swollen, distorted hepatocytes whose plasma membranes are still intact. The cells are no longer attached, their mitochondria are swollen and the cells contain vesicles of swollen RER. Note the sparse appearance of the endothelium in the sinusoid at the right and the lack of microvilli in the space of Disse (4000X). (B) Shows changes similar to those in (A). Note fragmenting of microvilli and the numerous but intact RBC's (6000X).

The cellular damage seen in Figures 16 and 17 are identical to that caused by toxic NRC- 1 extracts as shown in previous Figures. 

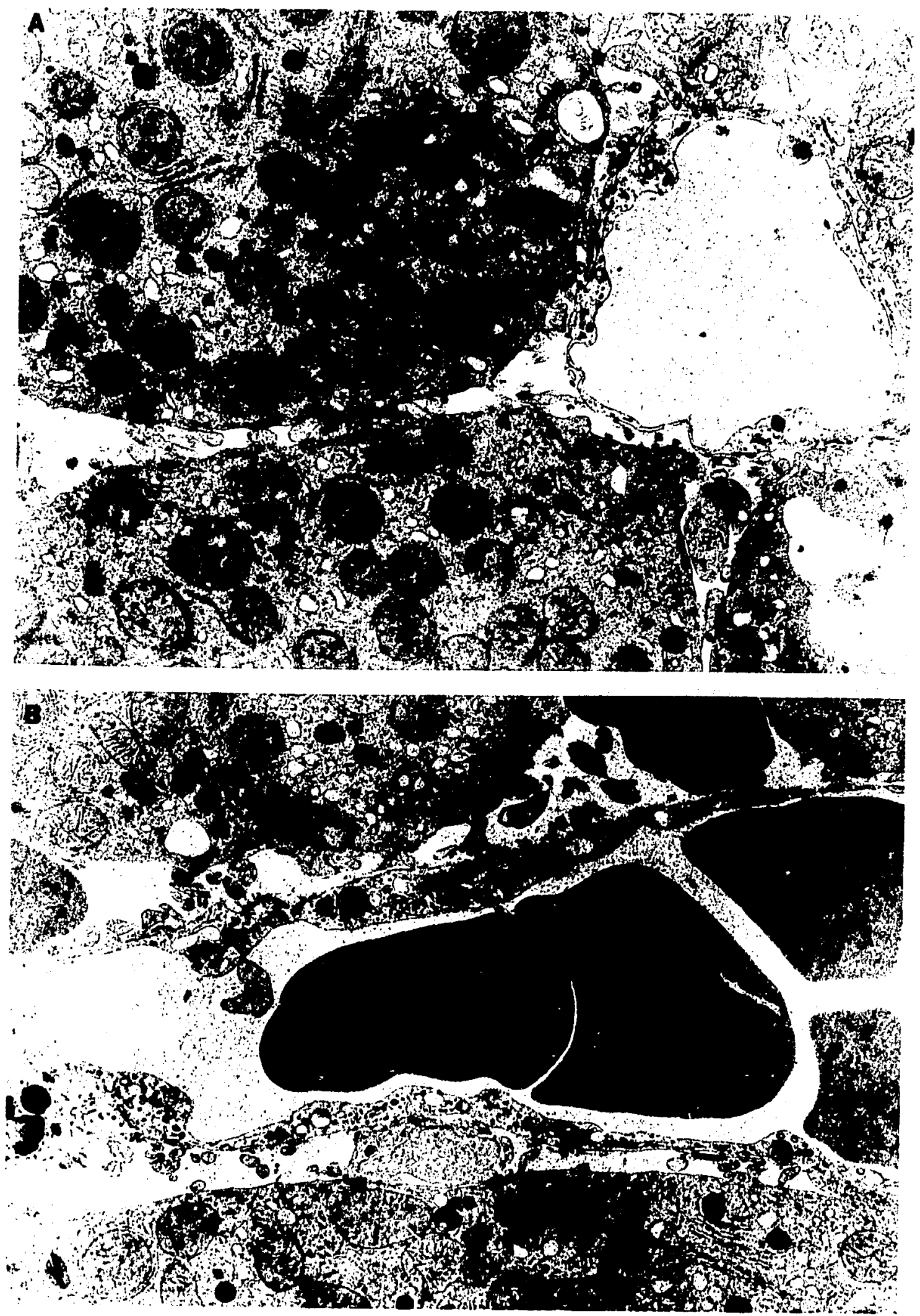
Figure 13.

Mouse liver exposed to toxic NRC-1 extract for 40 minutes.

(A) Note hepatocyte cytoplasm and its contents, they do not seem distorted except for mitochondrial swelling. The distorted $\mathrm{RBC}$ is surrounded by indistinct endothelium and microvilli are compressed and distorted (7500X). (B) Many RBC's are seen mixed with cytoplasmic contents released from hepatocytes. Lipid droplets, rounded mitochondria and individual rosettes of glycogen are visible but it is noted that the glycogen is not pooled in separate areas and large accumulations of RER are not present. Limiting membranes cannot be seen (4500X). (C) Similar to (B) but with the faintest remnants of a plasma membrane just visible above the RBC's (4000X). (D) Shows again the loss of intact cells. Hepatocyte components are mixed with RBC's (6000X). 


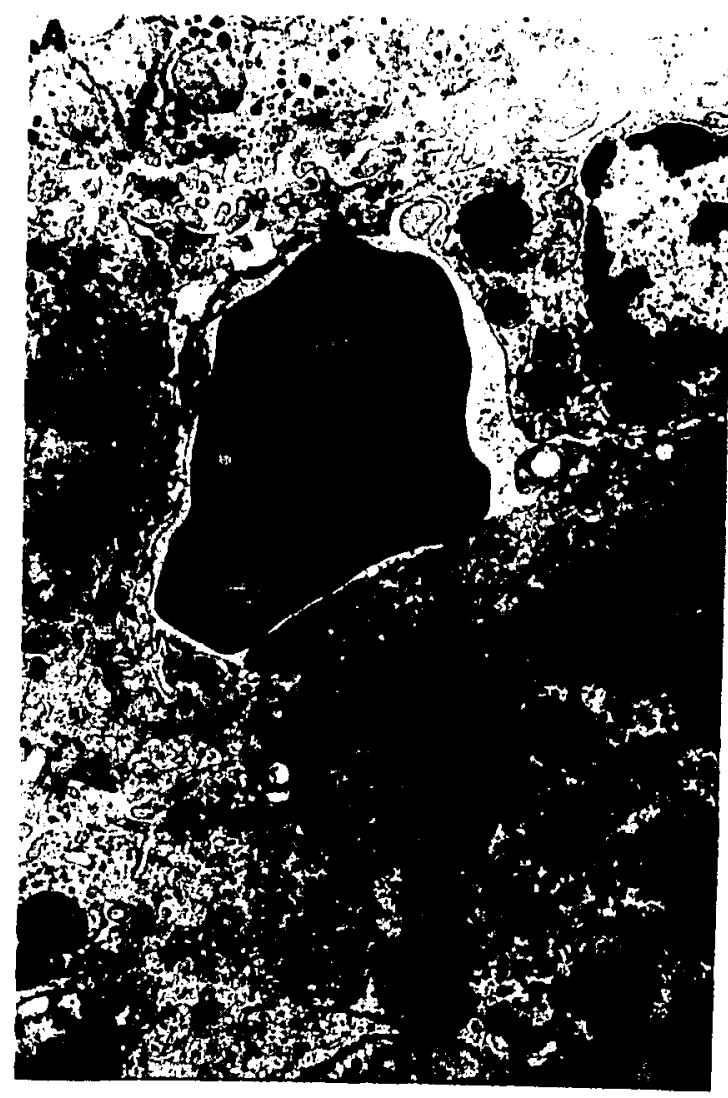

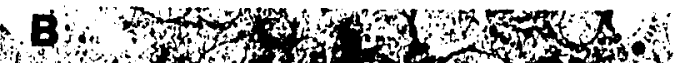

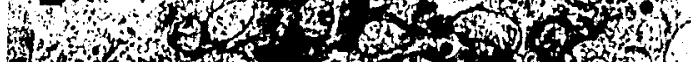
140 .

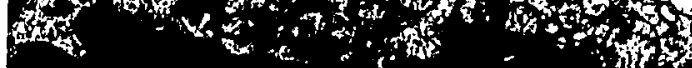
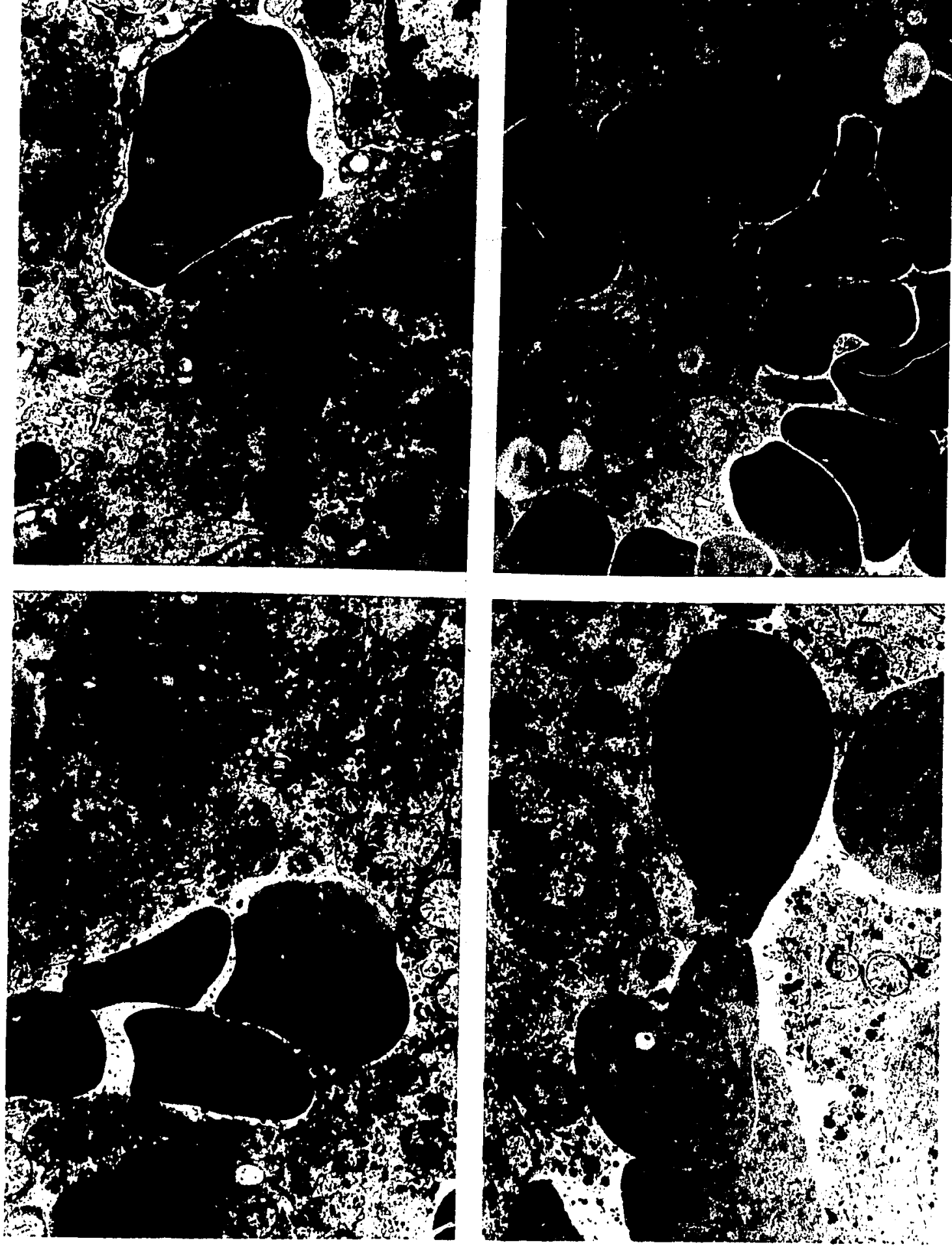


\section{Figure 14.}

Mouse liver exposed to toxic NRC-1 extract for 40 minutes.

(A) Sinusoidal area where endothelial and hepatocytic membranes have 1ysed, and there are pooled blood cells and cytoplasmic components. These micrographs and those of Fig. 12 illustrate the massive hemorrhaging that takes place in poisoned liver tissue (6000X). (B) A single $\mathrm{RBC}$ and membrane fragments that appear to have vesiculated. There is a loss of cytoplasm around contorted microvilli $(10,000 \mathrm{X})$. (C) A higher magnification of the damage but note the intact mitochondria, fragments of RER, glycogen rossettes, etc. that have spilled from the cells $(15,000 \mathrm{X})$. (D) This is a good illustration of the nature of toxin damage. The $\mathrm{RBC}$ and cell components are intact but distorted while the plasma membranes are broken apart and vesiculated. Note mitochondria, endoplasmic reticulum with attached ribosomes (RER), glycogen particles, etc. $(25,000 \mathrm{X})$. 

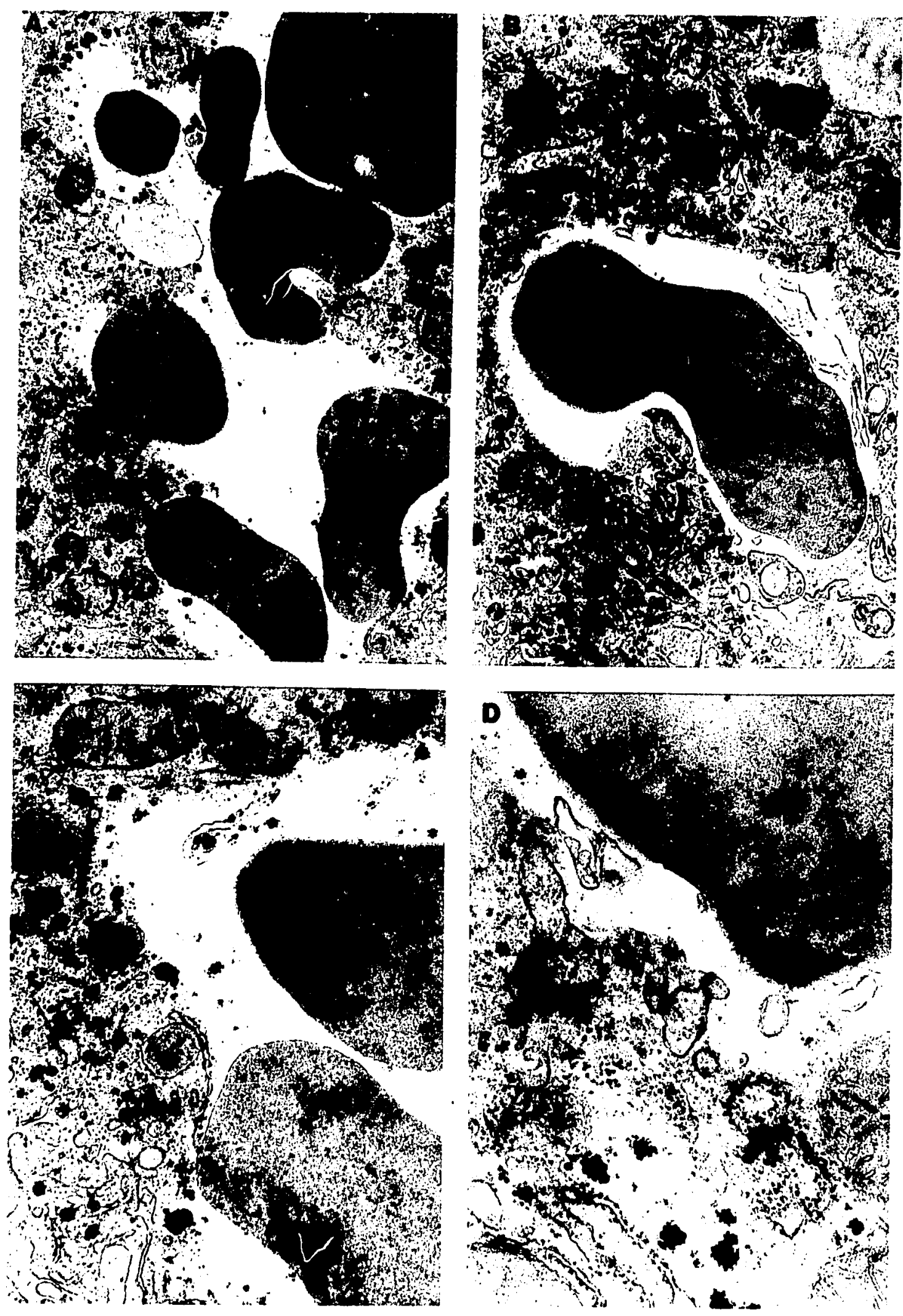
Figure 15.

Mouse liver exposed to toxic NRC-I extract for 20 minutes.

(A) No changes in hepatocyte organelles or inclusions is observed (4500X). (B) Shows a RBC in a sinusoid that has swollen, distorted and fragmented endothelium (6000X). (C) A $\mathrm{RBC}$ in a sinusoid where the changes in epithelium are seen more clearly. The endothelium is greatly swollen, the cells appear washed out, darkly staining material can be seen adjacent to the RBC and the microvilli in the space of Disse appear to be compressed. The plasma membrane of the endothelial cell(s) appears discontinuous $(9000 \mathrm{X})$. (D) Note that the cytoplasm and $i$ ts contents do not appear distorted in the hepatocyte, the $\mathrm{RBC}$ in the sinusoid is intact but the endothelium has fragmented into discontinuous, darkly staining pieces of membrane. Microvilli are distorted and there is darkly staining material around them $(7500 \mathrm{X})$. (E) The endothelium appears to have completely fragmented, hepatocyte plasma membranes are more difficult to distinguish and microvilli are greatly distorted (4500X). (F) A high magnification showing a RBC (lower left) and a portion of one hepatocyte (upper right). Microvilli are swollen and surrounded by amorphous material. Note the long fragment of membrane between the $\mathrm{RBC}$ and the microvilli $(25,000 \mathrm{X})$. 
A 3 or

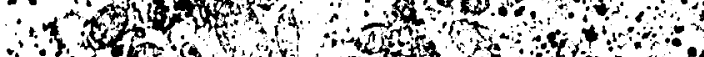

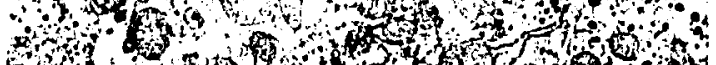

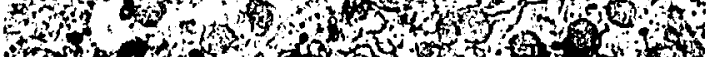

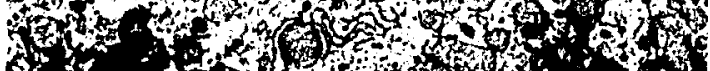

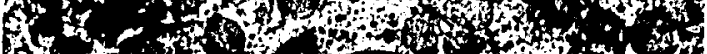

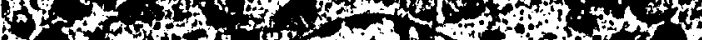

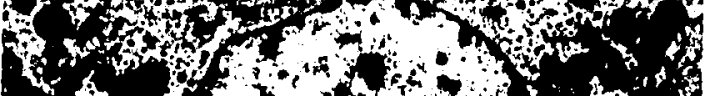

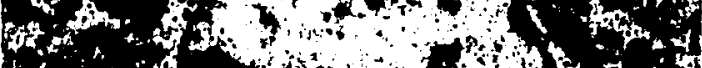

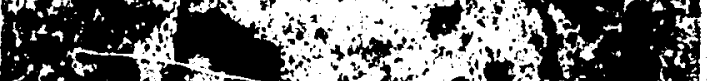
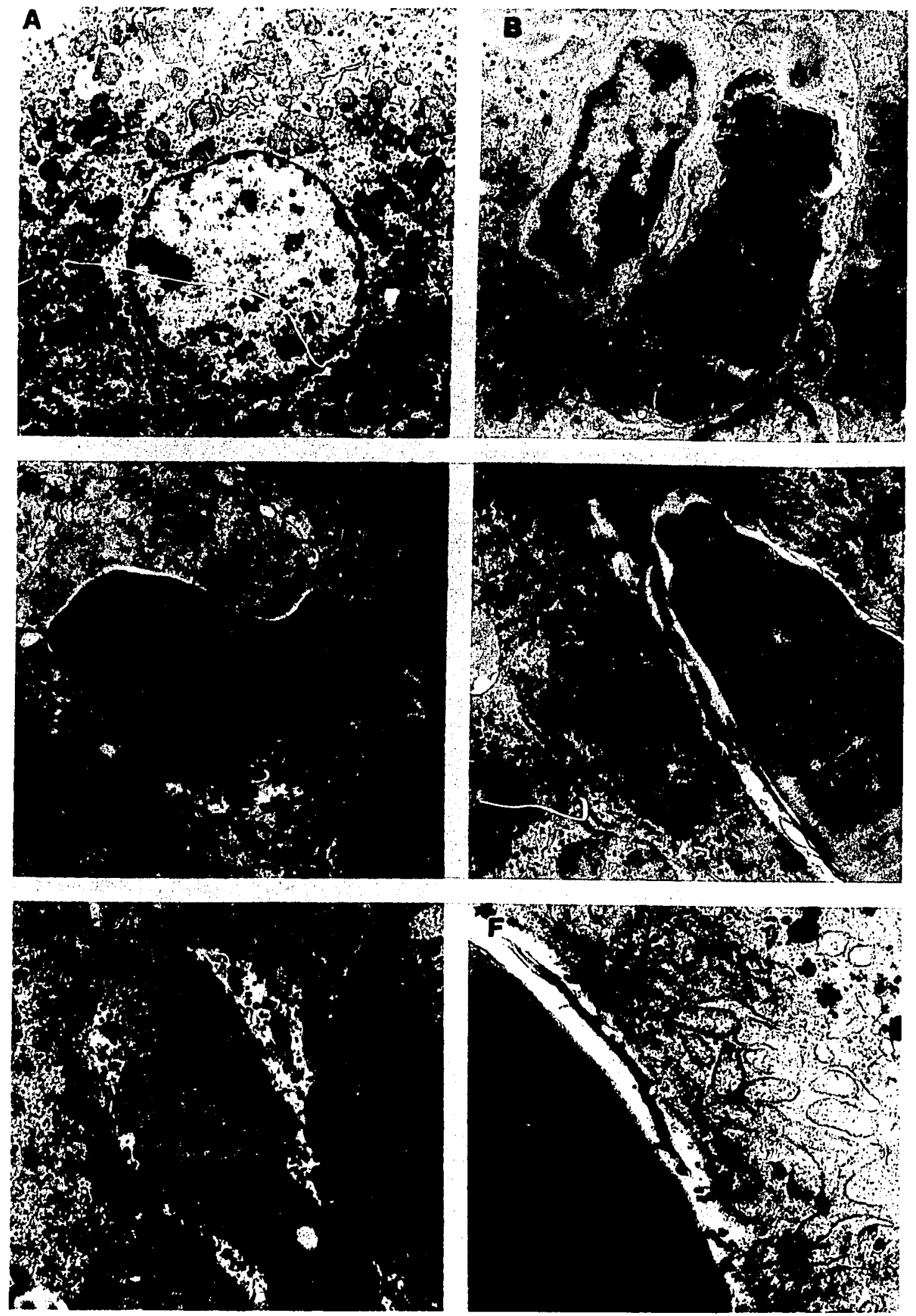
Figure 16.

Mouse liver tissue exposed to toxic NRC-1 extract for 10 minutes. (A) No noticeable changes in the nuclei, RER, mitochondria, glycogen content, or lysosomes are observed (4500X). (B) Sinusoids contain numerous membrane vesicles. Endothelium is intact as are microvilli and hepatocytes. No distortions of these structures are visible $(4500 \mathrm{x})$. (C) A higher magnification of a sinusoid containing several RBC's (7500X). (D) A more magnified micrograph of a sinusoid showing the membranous vesicles that are common even at this time $(10,000 \mathrm{X})$. 

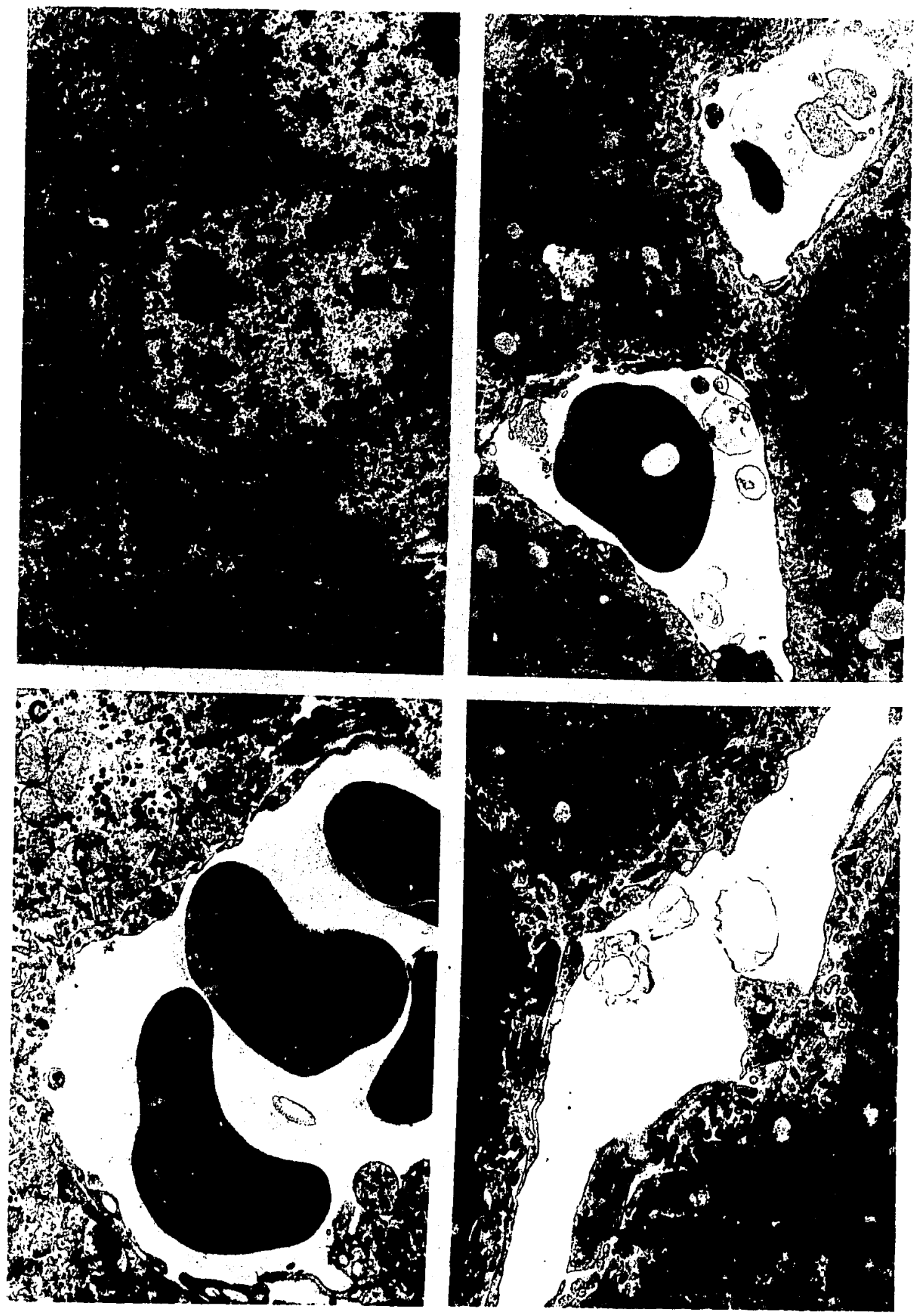
Figure 17.

Primary cultures of explants from neonatal mouse liver. (A) Untreated control, (B) control treated with non-toxic $M$. aeruginosa extract, (C) and (D) explants treated with toxin for 60 minutes, (E) and (F) explants treated with toxin for 90 minutes. AIl are $400 \mathrm{X}$ and were stained with $\mathrm{H}$ and $\mathrm{E}$. 


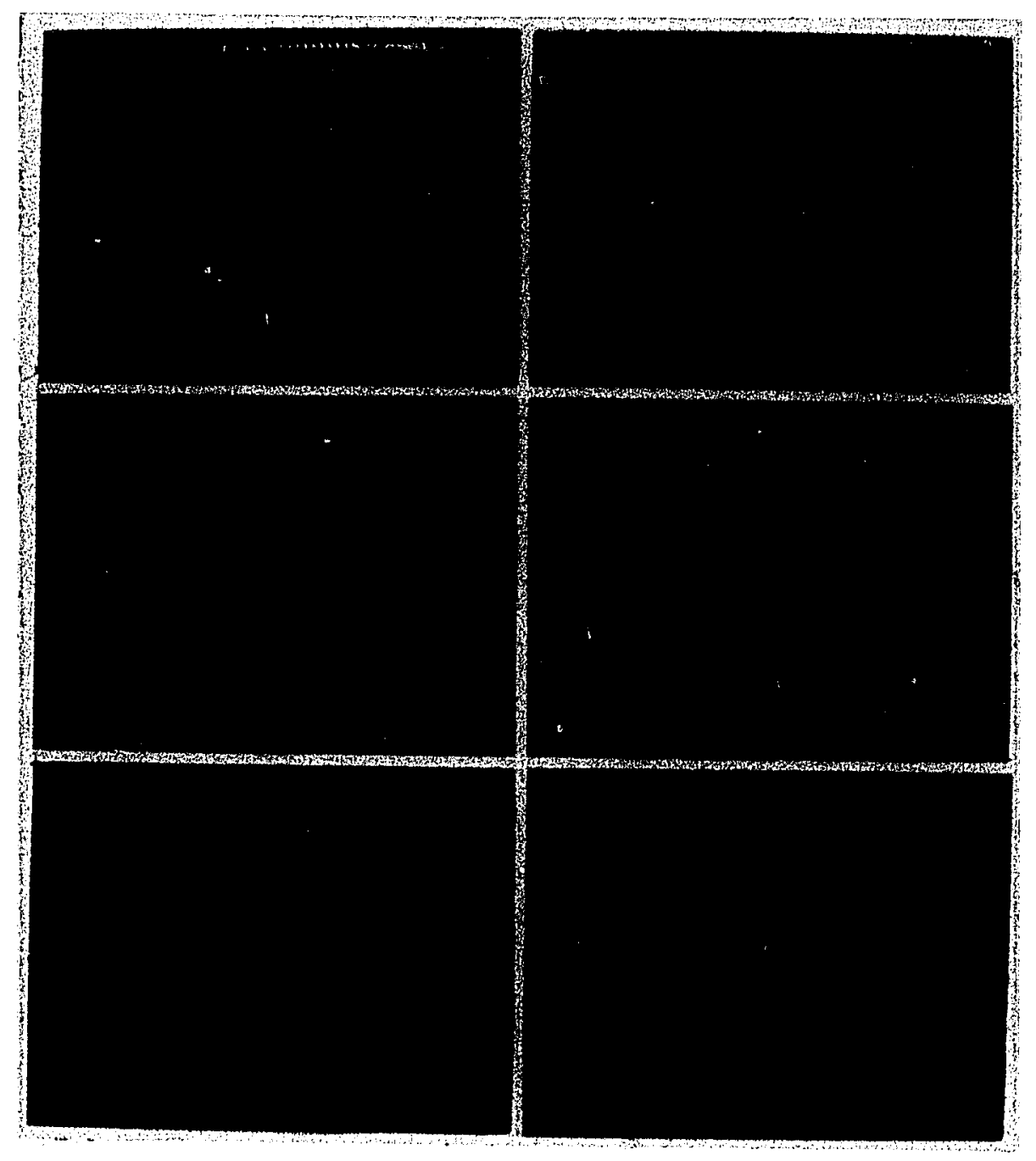




\section{DISCUSSION}

Reports on microcystin (FDF) are often ambiguous, in contrast to one another, or difficult to interpret. These anomalies may be due to several factors: (a) a lack of standardized material for testing and/or specific assay methods for the qualitative-quantitative determination of microcystin, (b) the unavailibility of more sophisticated techniques at the time the research was done, and (c) the use of extracts from mixed algal-bacterial samples. The present study confirms some areas of conflict and ambiguity and more specifically describes the site and mode of action of microcystin.

One area of uncertainty concerns the species affected by microcystin. Stangenberg(1967) reported no toxic effects from Microcystis on Daphnia. Maloney and Carnes (1966) found butanol extracts of Microcystis aeruginosa to be non-toxic to fish, Daphnia, and diatoms. Solomatina and Matchinskaya (1972) reported biochemical changes in fish exposed to "lethal" quantities of a blue-green mixture that was predominantly $\underline{M}$. aeruginosa. Malyarevskaya, et al., (1972) also used mixed algal cultures that contained mostly $\underline{M}$. aeruginosa and produced death in fishes. As noted earlier, these experiments used algal mixtures and it may be that other toxic substances were present in the other species, that there was a synergistic effect from several substances, or that parameters of water chemistry contributed to fish mortality. The results of the present study confirm the non-toxicity of microcystin to Daphnia and further show a nontoxicity to fish, whether they were exposed to it externally or 
or challenged (i.p.) in the laboratory. Algal mixtures were not used and doses were comparable to those that killed much heavier mammals. Malyarevskaya, et a1., (1972) noted biochemical changes in some of the test fish and although this phenomena was not examined, it would be difficult from their procedures to attribute these changes specifically to microcystin. Death or erratic behavior was not observed in fish during blooms of toxic $\underline{M}$. aeruginosa in New Hampshire.

Mason and Wheeler (1942) reported that frog hearts perfused with FDF went into immediate systolic arrest after the administration of even minute doses. The present work has shown microcystin to be non-toxic to both tadpoles and adult frogs whether immersed in toxic solutions or injected $i . p$. No effects were recorded when frog hearts were perfused in vivo or injected into the heart cavities.

The work of Hughes, et a1., (1958) and Bishop, et a1., (1959) suggested that the structure of microcystin may be very similar to that of many peptide antibiotics. Bishop, et al., (1959) reported that the molecule had no antibacterial activity. This was confirmed using extracts from the N.H. strain of Microcystis aeruginosa. In addition, the active materials failed to show any activity against a green alga, yeast, and gram negative and gram positive bacteria. Since antibiotics are derived from microorganisms it is interesting to examine substances that may be chemically similar for any such biological activity.

In addition to the above test species, microcystin was also used against other organisms important in freshwater ecosystems. 
Neither crayfish (Cambarus) not a freshwater teleost (Carassius auratus) showed any adverse effects from either immersion or injection with microcystin.

The above observations indicate that release of the toxin from growths of Microcystis aeruginosa would not have a directly toxic effect on a wide variety of freshwater organisms. This does not, however, preclude the indirect effects that might result from decreased oxygen content of the water, $\mathrm{pH}$ changes, sunlight availability, etc.

Those species sensitive to microcystin (FDF) appear to be limited to the classes Aves and Mammalia. The experiments with mice have shown that death is not accompanied by convulsions as occurs with neurotoxins from cyanobacteria such as Aphanizomenon flos-aquae (Sawyer, et al., 1968). Since other cyanophytes do produce neurotoxins, experiments were conducted to determine whether or not microcystin had activity against excitable membranes. In repeated experiments conducted for periods of time longer than would be fatal in vivo, no effects could be found on excitable tissues, i.e., nerves and muscles. Isolated smooth muscle preparations using mouse small intestine, in vivo mouse heart experiments, frog sciatic nerve, and frog sartorius muscle preparations all gave experimental results identical to the control results. Therefore, microcystin is not a nerve or muscle poison and should not be expected to produce symptoms in mice or other animals indicative of such poisons.

Physiological and pathological effects from microcystin however, have been described in organs other than the liver. The 
literature provides conflicting information on this matter. The observations made in this study suggest that extra hepatic damage after microcystin poisoning results from indirect or secondary effects after primary liver damage. Mason and Wheeler (1942) described circulatory changes in small animals that included decreased blood pressure, hematocrit, hemoglobin leve1, RBC count, and total serum protein. These changes, and the often observed decreased peripheral circulation (Konst, et al., 1965) could have resulted from the massive hemorrhaging into the liver that was observed in all accounts of microcystin intoxication. The present study demonstrated significant hepatic volume and weight changes due to blood accumulation. The results of the histological and ultrastructural studies provided ample evidence for the accumulation of large amounts of blood in poisoned livers. Gorham (1962) reported swelling of the right ventricle in mammals exposed to the toxin and Heaney (1971) reported small hemorrhages in the lungs. However, Konst, et al., (1965) observed normal heart morphology except for occasional slight swelling. The heart may be under extreme stress during microcystin poisoning and occasional secondary effects on this organ could be symptomatic of this stress. In the present study, no effects were noted on vital organs other than the liver. There was no swelling, bleeding, color change, or distortion in shape or size, and no histological lesions were found in any of the eight organs examined.

Mason and Wheeler (1942) provide some indirect evidence to support these findings when they reported that oxygen consumption of isolated kidney, diaphragm, and brain tissues was not effected 
by toxin concentrations that were lethal in vivo. Ashworth and Mason (1945) did not detect changes in the weight of the heart, lungs, spleen, or kidneys in acutely poisoned animals and except for a few small hemorrhages in the lungs, no lesions were seen in these organs.

Ashworth and Mason (1945) examined the effects of chronic doses of microcystin on mice and made histological studies of vital organs at different time periods after exposure. The heart (after 2 hours) showed some swelling and an increased granularity of fibers. Slightly swollen and hyalinized muscle fibers were present in the left ventricle. A few small hemorrhages were noted below the endocardium and in the myocardium; this was most marked at 4 hours. No cardiac changes were noted after 3 to 5 days. The lungs were only slightly involved; there was equivocal alveolar involvement that consisted of focal, slight alveolar hemorrhages. The kidney showed its earliest alteration after 20 minutes. It displayed marked patchy, cortical hyperemia. There was swelling, increased granularity and loss of the distinct luminal. border of the tubular epithelium. The spleen, adrenals, and brain showed no histological changes. These authors concludede that tissue damage was not confined to the liver but also caused degeneration and cell death in other organs. In my opinion, chronic-dose studies do not clearly support the hypothesis that organs, other than the liver, are specific sites of action for nicrocystin. The rapid and extensive liver damage observed in this--and in previous work--may have initiated such significant physiological stress and blood chemistry changes that the obser- 
vations outlined above would inevitably lead to secondary effects. These same authors mention the early parenchymatous degeneration of heart and kidneys and the extreme rapidity of action by microcystin on liver. From the chronology of their results it is noted that hepatic damage always precedes damage to the other organs, in many cases by several hours. The latter suggests that microcystin exerts a direct effect on the liver but that the changes in other organs are a result of liver damage. Hepatocyte destruction could add intracellular components to the blood bathing other organs and over time may cause elevated enzyme leveis, salt concentrations, and metabolic products, resulting in damage to the kidneys, heart, and/or lungs. These secondary effects could result from osmotic changes, acid-base imbalances, direct enzymatic action, and associated metabolic changes. Petechial hemorrhages in the heart and kidneys could also result from, or be exacerbated by, changes in the clotting mechanism brought about by liver destruction. Abnormal material in the kidney tubules could be due to the excretion of substances capable of damaging tubular epithelium, the ultrafiltration of excess material in the blood across the glomerulus without reabsorption, or changes in glomerular filtration resulting in conditions such as proteinuria. This would account for the darkly staining, amorphous material in the lumen of the tubules.

The early histological studies revealed much about the effects of microcystin at the tissue level but did not give specific information regarding effects at the cellular-subcellular level. Many histological descriptions are very general in nature, 
i.e., noting events such as cell swelling, cloudy cytoplasm, granularity, etc., and not revealing what is happening within the ce1l(s). This level of technical limitation was as far as toxicity studies had progressed. The intent of this work was to provide further details on the site and character of hepatocyte degeneration and necrosis.

Figures 8 through 16 show the damage occurring at the cellular/ subcellular level. There was endothelial cell swelling and lysis without obvious changes in intracellular components. This appeared to be the result of membrane damage and resulted in the appearance of membrane fragments, vesicles, and myelin figures in the sinusoids as early as 10 minutes after i.p. injection. Hepatocytes did not show any obvious intracellular changes either, except for a slight swelling of mitochondria. Mitochondria did not have distorted cristae, there was no enlargement of the space between the two limiting membranes, there were no unusual intramitochondrial inclusions, no changes in the matrix material, and no mitochondria were observed to rupture. It could have been that damage to the plasma membrane resulted in osmotic changes to which the mitochondria responded or that cellular stress brought about metabolic perturbations that altered mitochondrial morphology. It has been established that mitochondrial conformation changes with metabolic state (Lehninger, 1975). There was no swelling of rough endoplasmic reticulum (RER) and no unusual material was noted in the cisternae of RER. There were no alterations in the number or pattern of ribosomes on the surfaces of the RER. No increase in the amount of smooth endoplasmic reticulum (SER) was noted, nor 
were there changes in the number or morphology of lysosomes or lipid droplets. Glycogen content of hepatocytes did not change until the cells lysed and even then the conformation of glycogen particles and number was unaltered. There were no noticeable nuclear or nucleolar changes. One or more of these alterations are common in liver tissue acutely exposed to toxic substances, when there is chronic exposure to irritating chemicals or when various diseases have affected the organism (Trump, et al., 1975). It may be that some of the observations in the histological studies of chronic exposure to microcystin produced such cellular effects, but in acute poisonings there is not enough time for these changes to occur. Hepatocytes displayed surface changes as seen not only in the distortion (broadening and shortening) of microvilli but along the detached surfaces where bile canaliculi are located. Microcystin absorbed into the circulatory system would quickly reach the liver where endothelial (reticuloendothelial) cells would be exposed first to the toxin. Fenestrations in the endothelium (and its lysis) would permit the toxin to move rapidly to the parenchymal liver cells and the first cell surface in contact with it would be the one in the space of Disse. Here the plasma membrane on the microvilli would be the cell component of hepatocytes first effected. The micrographs show that this is most probably the sequence of damage. Endothelial swelling and lysis was followed by hepatocyte swelling, changes in the hepatocytic surface in the space of Disse, and hepatocytic lysis with the spilling of cytoplasm into what was the sinusoidal cavity. At this stage 
the cytoplasm of hepatocytes was found mixed with intact RBC's. Sinusoids are the specialized capiliaries of the liver and central veins are also an integral part of its circulation. The destruction of these structures was the most likely cause of the massive hemorrhaging in the liver.

Hepatocytes surrounding the central veins were effected first and the damage then spread out toward the lobule periphery. It has been established (most significantly in mice) that, due to blood circulation patterns in the liver, hepatocytes in areas adjacent to central veins are different metabolically from those in the middle areas or at the periphery of lobules. The cells near the central veins are the last to receive oxygen and nutrients and may be more sensitive to the deleterious effects of toxic substances (Bloom and Fawcett, 1970). Thus, it may be that the centrilobular hepatocytes in mouse liver are the least resistent to microcystin and that, as the length of exposure and the amount of damage increases, the cells further away from the central vein are effected.

It now appears that microcystin is 1ysing specific membranes in mouse liver. "An obvious criterion of a cytolytic effect is the prompt physical dissolution or disruption of mammalian or other kinds of cells in vitro." (Bernheimer, 1970). The best illustration of this disruption is the 1ysis of erythrocytes but this did not occur in mice poisoned with microcystin and was one of the major reasons for conducting studies with isolated mouse hepatocytes in vitro. Cell culture techniques are now used extensively in studies of cytolytic agents and yet microcystin did not cause lysis of neo- 
natal cells in liver microexplants. This observation led to the studies of the toxin's effects with' age and the finding that prenatal and neonatal mice were not effected. Gross symptoms did not occur and histological lesions did not appear before the mice were approximately twenty days old. Until this time there were no observable differences between controls and toxin injected animals. A similar resistance in young mammals has been noticed with other toxins, one example of which is phalloidin. This is also a hepatocyte lysing toxin and is produced by the poisonous mushroom Amanita phalloides (Wieland and Faulstich, 1978).

As early as 1946, Ashworth and Mason pointed out the similarities in chemical properties, pathological effects and composition between Amanita and Microcystis toxins. Phalloidin is also a cyclic peptide that acts specifically on hepatocyte membranes but its ultrastructural pathology involves cell vacuolization which is different from the effects observed here.

No attempt was made to determine the reason(s) for the resistance of younger animals but it may be that certain cell components or functions (e.g., receptor molecules, enzyme systems, etc.) that are important in the toxin's mechanism of action had not developed yet or had not been activated.

Ultrastructural pathological studies in poisoned animals can show early changes in organelles or inclusions that indicate a specific site of action and give information about specific biochemical effects. Ultrastructural studies with amanitin showed nucleolar changes and further investigations established that the toxin inhibited RNA polymerase (Wieland and Faulstich, 1978). 
Changes in RER or free ribosomes could indicate effects on protein synthesis, changes in lipid content could indicate a change in lipid metabolism, and alterations in golgi or lysosomes could indicate that these organelles and their particular functions were being impaired, etc. In the case of Microcystis toxin, no subcellular changes were noted except for plasma membrane disruption. Since there is rapid destruction of cell membranes without preceding intracellular changes, it seems that the plasma membrane of liver cells is the site of action of microcystin. The promptness of action, the discontinuities in cell membranes, the rupture of cells with the release of cytoplasm, and the presence of membrane fragments and vesicles in the initial stages of intoxication all support this conclusion. Microcystin can therefore be described as a cytolytic toxin. As with all toxins "The primary criterion for a cytolytic toxin should . . be based on the evidence that the damage is specifically confined to the cytoplasmic membrane accompanied by loss of morphology and/or functional integrity of the osmotic barrier with concomittant leakage of intracellular materia1." (Alouf, 1976). Microcystin certainly fits this description.

Although the exact mechanism of membrane destruction is still unknown, there are some distinct possibilities. If this toxin, upon further chemical characterization, is proved to be a cyclic peptide as is currently believed, it may be acting as an ionophore carrying ions through the hydrophobic lipid bilayer of the cell membrane thus creating an osmotic imbalance. This could result in swelling and eventual rupture of the hepatocytes. The different 
biochemical composition of $\mathrm{RBC}$ membranes could account for the fact that they are unaffected. The lack. of effects on other cells in other vital organs and the lack of effects on microorganisms other than Microcystis do not support this hypothesis. The toxin might also bind to receptor molecules on the membrane surface and create aggregates of receptor-toxin complexes that put tension on the membrane, cause it to open locally and therefore change its permeability. Orlovski and Kirpenko (1976) reported that the toxin produced disturbances in the oxidation of carbohydrates and suggested that this was one of the links in the mechanism of its action. It would seem that such a metabolic alteration would produce changes more slowly than does microcystin and that intracellular structural changes would occur prior to cell 1ysis. Perhaps the authors were noting metabolic changes resulting from the destruction of hepatocytes and all of the post-1ytic biochemical changes. All evidence to date points to the cell membrane of liver cells as the site of action and it appears that microcystin acts as a lytic agent on these membranes.

To understand the basis of intoxication and its treatment it is necessary to understand the cellular-subcellular alterations that are produced by the poison involved. Indeed, all major manifestations of disease reflect changes in cellular-subcellular morphology and physiology. It is at the organelle and macromolecular level that detailed correlation between structure and biochemistry is possible in disease states. Thus, it is possible to describe disease (or poisoning) as affecting mitochondria, lysosomes, cell membranes, etc. This study has more specifically described the 
site of action of microcystin and further characterized its pathology. It is hoped that this work can provide a basis for future research on the exact mechanism of this toxin's action. 


\section{Bibliography}

Alouf, J. E. 1976. Cell Membranes and Cytolytic Bacterial Toxins. In: Cuatrecasas (ed.), The Specificity and Action of Animal, Bacterial and Plant Toxins (Receptors and Recognition, series

B, Vol. I). London, Chapman and Hall. pp. 221-264.

Ashworth, C. T. and M. F. Mason. 1946. Observations on the pathological changes produced by a toxic substance present in blue-green algae (Microcystis aeruginosa). Am. J. Pathology. 22 (2):369-380.

Aziz, K. 1974. Diarrhea toxin obtained from a waterbloomproducing species, Microcystis aeruginosa Kutzing. Science $\underline{183}: 1206-1207$.

Bishop, C. T., E. F. L. J. Anet and P. R. Gorham. 1959. Isolation and identification of the fast-death factor in Microcystis aeruginosa NRC-1. Can. J. Biochem. Physio1. 37:453-471.

Carmichae1, W. W., D. F. Biggs and P. R. Gorham. 1975. Toxicity and pharmacological action of Anabaena flos-aquae toxin. Science 187: 542-544.

Cessi, C. and L. Fiume. 1969. Increased toxicity of B-amanitin when bound to a protein. Toxicon. $\underline{6}: 309-310$. 
Collins, M. 1978. Algal toxins. Microbiological Reviews. 42(4): $725-746$.

Drouet, F. and W. A. Daily. 1956. Revision of the coccoid Myxophyceae. Butler Univ. Botan. Studies. 12:1-218.

Echlin, P. 1966. The blue-green algae. Sci. Am. 214(6):75-81.

Fitch, C. P., L. M. Bishop, W. L. Boyd, L. A. Gortner, C. F. Rogers and J. E. Tilder. 1934. "Water bloom" as a cause of poisoning in domestic animals. Corne11 Vet. 24 $(1): 30-39$.

Gorham, P. 1960. Toxic waterblooms of blue-green algae. Can. Vet. J. $1: 235-245$.

Gorham, P. R. 1962. Laboratory studies on the toxins produced by waterblooms of blue-green algae. Am. J. of Public Health. $\underline{52}(12): 2100-2105$.

Gorham, P. R. 1964. Toxic a1gae. In: D. F. Jackson (editor). Algae and Man. Plenum Press, New York. pp. 307-337.

Grant, G. A. and E. O. Hughes. 1953. Development of toxicity in blue-green algae. Can. J. of Public Health. 44:334-339.

Heaney, S. I. 1971. The toxicity of Microcystis aeruginosa Kutz. from some English reservoirs. Water Treatment and Examination. $\underline{20}(4): 235-244$. 
Hughes, E. O., P. R. Gorham and A. Zehnder. 1955. Toxicity of Microcystis aeruginosa in pure culture. Phycological News Bu11. $\underline{8}(5): 5$.

Hughes, E. O., P. R. Gorham and A. Zehnder. 1958. Toxicity of a unialgal culture of Microcystis aeruginosa. Can. J. Microbiol. 4: 225-236.

Ingram, William Marcus and G. W. Prescott. 1954. Toxic freshwater algae. The American Midland Naturalist. 52(1):75-87.

Kirpenko, Yu A., I. I. Perevozchenko, K. A. Sirenko and L. F. Lukina. 1975. Isolation of toxin from blue-green algae and some of its physiochemical properties. Adademiia Nauk USSR, Kiev. Dopovidi. Serri B. Geologiia, GeoFizika, K?.uimiia ta Brologiia, Kiev. No. 4, pp. 359-361.

Konst, H., P. D. McKercher, P. R. Gorham, A. Robertson, and J. Howell. 1965. Symptoms and pathology produced by toxic Microcystis aeruginosa NRC-1 in laboratory and domestic animals. Can. J. Comp. Med. and Vet. Sci. 29:221-228.

Kraus, M. P. 1966. Preparation of pure blue-green algae. Nature. $\underline{211}: 310$.

Krebs, K. G., D. Heusser and H. W. Wimmer. 1969. Spray Reagents. In: E. Stahl (ed.), Thin-Layer Chromatography: A Laboratory Handbook. 2nd Ed. New York: Springer-Verlag. pp. 854-909. 
Louw, P. G. J. 1950. The active constituent of the poisonous algae, Microcystis toxica Stephens. S. African Industrial Chemist. $4: 62-66$.

Maloney, T. and R. A. Carnes. 1966. Toxicity of a Microcystis waterbloom from an Ohio pond. Ohio J. Cit. 66 (5):514-517.

Malyarevskaya, A. Ya., T. I. Birger, O. M. Arsua, and V. D. Solomatina. 1972. Metabolic relationships between bluegreen algae and fish. Gidrobiol. Z H. $\underline{8}(3): 47-55$.

Marinozzi, V. and L. Fiume. 1971. Effects of $\alpha$-amanitin on mouse and rat liver cell nuclei. Exp. Cel1 Res. 67:311-322.

Mason, M. F. and R. E. Wheeler. 1942. Observations upon the toxicity of blue-green algae. Fed. Proc. $1(1): 124$.

May, Valerie. 1970. A toxic alga in New South Wales and its distribution. Contrib. from the New South Wales Nationa1 Herbarium. $\underline{4}(3): 84-86$.

McBarron, E. J. and V. May. 1966. Poisoning of sheep in New South Wales by the blue-green alga Anacystis cyanea (Kuetz.) Dr. and Dail. Australian Vet. J. 42:449-453.

McLachlan, J. and P. R. Gorham. 1961. Growth of Microcystis aeruginosa Kutz. In a precipitate-free medium buffered with Tris. Can. J. Microbiol. $\underline{7}: 869-882$. 
McLachlan, J. and P. R. Gorham. 1962. Effects of pH and nitrogen sources on growth of Microcystis aeruginosa Kutz. Can. J. Microbio1. $\underline{8}(1): 1-11$.

Miller, R. and 0. Wieland. 1967. Electron microscopic studies of mouse and rat hepatic cells after acute phalloidin poisoning. Virchows Arch. Path. Anat. Physio1. K1in. Med. 343:83-99.

Moore, R. E. 1977. Toxins from blue-green algae. Bioscience. $\underline{27}(12): 797-802$.

Murthy, J. R. and J. B. Capindale. 1970. A new isolation and structure for the endotoxin from Microcystis aeruginosa NRC-1. Can. J. Biochem. 48:508-510.

Olson, T. A. 1951. Toxic plankton. Proceedings of inservice training course in water works problems. Ann Arbor, Mich.

Orlovskii, V. M. and Yu A. Kirpenko. 1976. Biologically active metabolites of blue-green algae and their effect on experimental animals. Gigiena I Sanitariya. 3:13-17.

Prescott, G. W. 1948. Objectionable algae with reference to the killing of fish and other animals. Hydrobiologia. 1:1-3.

Rose, Ear1 T. 1953. Toxic algae in Iowa Lakes. Iowa Academy of Science. 60:738-745. 
Sasner, J. 1973. Comparative studies on algal toxins. In: D. Martin and G. Padilla (ed.), Marine pharmacognosy. Academic Press Inc., New York. pp. 127-177.

Sawyer, P., J. Gentile and J. Sasner. 1968. Demonstration of a toxin from Aphanizomenon flos-aquae (L.) Ralfs. Can. J. Microbiol. 14:1199-1204.

Schwimmer, D. and M. Schwimmer. 1964. Algae and medicine. In: D. Jackson (ed.), Algae and Man. Plenum Publishing Corp., New York. pp. 368-412.

Shelubsky, M. 1951. Observations on the properties of a toxin produced by Microcystis. Verhandl. int. Ver. Limnol. 11: $362-366$.

Simpson, B. and P. R. Gorham. 1958. Source of the fast death factor produced by unialgal Microcystis aeruginosa NRC-1. Phycological Soc. Am. News Bull. 11:59-60.

Solomatina, V. C. and S. F. Matchinskaya. 1972. Alteration of the amino acid content of the ide induced by blue-green algae. Hydrobiological J. $\underline{8}(4): 46-49$.

Stangenberg, M. 1968. Toxic effects of Microcystis aeruginosa $\mathrm{Kg}$. extracts on Daphnia Iongispina 0. F. Muller and Eucypris virens Jurine. Hydobiologia. 32:81-87. 
Stephens, E. L. 1949. Microcystis toxica sp. nov.: A poisonous alga from the transvaal and Orange Free state. Roy. Soc. S. Africa Transact. $\underline{32}(1): 105-112$.

Steyn, D. G. 1945. Poisoning of animals by algae (scum or waterbloom) in dams and pans. Union of S. Africa, Dept. of Agric. and Forestry. Gout Printer, Pretoria.

Thompson, W. K., A. C. Laing and G. A. Grant. 1957. Toxic algae. IV. Isolation of toxic bacterial contaminants. Report No. 51, Defence Research Board, Canada.

Trump, B. F. and A. U. Arstila. 1975. Cellular Reaction to Injury. In: LaVia and Hill (ed.), Principles of Pathology, 2nd Ed. New York, Oxford University Press. pp. 9-95.

Tolstopyatova, G. V. 1970. Toxic properties of blue-green algae. Hydrobiological J. $\underline{6}(1): 67-69$.

Vance, B. D. 1966. Sensitivity of Microcystis aeruginosa and other blue-green algae and associated bacteria to selected antibiotics. Phycol. 2: 125-128.

Vinberg, G. G. 1954. Toksicheskii fitoplankton. Uspeklin Sour. Biologii 38. $2(5): 216-266$.

Wheeler, R. E., J. B. Lackey and S. A. Schott. 1942. Contribution on the toxicity of algae. Pub. Health Report. 57:1695-1701. 
Wieland, T. and H. Faulstich. 1978. Amatoxins, phallotoxins, phallolysin and antamanide: the biologically active components of poisonous Amanita mushrooms. Critical Reviews in Biochemistry, Vo1. 5, Issue 3, p. 185-260.

Zehnder, A. and P. R. Gorham. 1960. Factors influencing the growth of Microcystis aeruginosa Kutz. Emand. Elankin.

Can. J. Microbiol. 6: 645-660. 


\section{APPENDIX I.}

Purification of the toxic peptide from the NRC-1 strain was attempted in order to do some of the above work with purified, or at least partially purified, microcystin. A chemical extraction was tried following the procedure of Bishop, et al. (1959), but compared to the original work, very small quantities of lyophilized Microcystis aeruginosa were used. These small amounts were used because of the quantities available. Although more than adequate for the cell-oriented studies, the supplies were not sufficient to start separations with amounts approaching those reported in the 1iterature. Control samples were from the non-toxic $\underline{M}$ aeruginosa and all samples were made up as described to the same concentration $(0.001$ gm dry wt/ml).

Extractions of aqueous solutions of 1yophilized NRC-1 were attempted with organic solvents: acetone, benzene, and chloroform, in order to remove pigment molecules from the solution.

Separation of toxin using thin layer chromatography (TLC) was tried as a possible means of toxin identification, as well as purification. TLC plates (Silica Gel 60) were activated in a $110^{\circ} \mathrm{C}$ oven for 30 minutes prior to use. Origins were $2 \mathrm{~cm}$ from the bottom of the plate and 10 microliters of the sample(s) to be run were spotted onto the plate using disposable, capillary micropipettes. Spots were air dried and fresh solvent was prepared for every other run. Two solvent systems were utilized: 1) Buthanol:Acetic Acid: Water (2:1:1), and 2) Pyridine:Ethy1 Acetate:Acetic Acid:Water $(50: 17: 20: 10)$. Plates were run in one dimension in glass chromato- 
graphy chimbers; at the end of the run the solvent front was marked, the time was noted, and the plates were air dried in a hood. The butanol solvent system became the one of choice due to greater resolution and less streaking.

Plates were sprayed using ninhydrin and followed by 0-tolidine regeant (Krebs, et al., 1969). Before spraying with 0-tolidine the plate had to be placed in a chlorine atmosphere for 15-20 minutes and then allowed to air dry in the hood for 30 minutes. This converted any amines to chloramines for reaction with 0-tolidine. AlI plates were examined under short and long wave u.v. light.

Ascending paper chromatography was done using $17 \times 30 \mathrm{~cm}$ strips of Whatman's No. 1 chromatography paper. Sample spotting was done as above, the butanol system was used, and ninhydrin and 0-tolidine were the developing sprays.

Electrophoresis on Whatman $3 \mathrm{~mm}$ paper $(19 \times 3 \mathrm{~cm}$ strips) and on cellulose acetate (0xoid, $16 \times 2.5 \mathrm{~cm}$ strips) was carried out using a plastic buffer tray with electrodes and a Buchler power pack set at $1.5 \mathrm{~mA}$ per strip. Several strips (of the same material) were often run simultaneously. A sample applicator was used to insure a uniform application at the origin and the sample was allowed to air dry prior to electrophoresis. Cold sodium carbonate:sodium bicarbonate buffer $(\mathrm{pH} 9.1)$ and borate buffer $(0.1 \mathrm{M}, \mathrm{pH} 9.2)$ were the electrolyte systems chosen based on the results of Bishop, et al. (1959), and Murthy and Capindale (1970). The samples were run for 2 hours, 1 hour, 20 minutes, and 10 minutes in separate trials. Development was with ninhydrin and 0-tolidine.

Removal of the samples from areas corresponding to those 
developed on the above media was attempted using water, the solvent systems employed, the buffer systems employed, and organic solvents of both a polar and a nonpolar nature. TLC plates were scraped and after crushing the Silica Gel, the areas for different spots were placed in separate test tubes and elution was attempted. Areas on paper chromatograms were cut out, cut into small pieces, and washed in beakers to elute the samples. The same procedure was used with electrophoretic strips. Aqueous elutions were injected i.p. into mice; at later trials they were concentrated down in vacuo. Organic elutions were dried in vacuo and redissolved in water prior to injection. Those samples that were eluted in buffer were, in some cases, concentrated by evaporation, but when this was done, the osmotic concentration was always measured before injection to be sure it was within a physiological range.

Because of the small sample sizes that had to be utilized, the more recently available technique of molecular filtration or sieving was attempted. Diaflo U1trafiltration Membranes (Amicon Corp., Lexington, MA) were used to filter $10 \mathrm{ml}$ aliquots using constant stirring with a magnetic bar and 30 psi nitrogen gas. The following molecular sieve sizes were used: 100,000, 50,000, 30,000, $20,000,1,000$, and 500 daltons. At the 10,000 dalton level, Immersible Molecular Separators (Millipore Corp., Bedford, MA) were used on house vacuum.

In many cases, the sample was brought down to $2 \mathrm{ml}$. This was done to try to wash the sample for more complete filtration. Samples were saved at each molecular weight level and either injected without further manipulation or concentrated in vacuo and injected i.p. into mice. 
Aside from aqueous aliquots, several filtrations were attempted in sodium phosphate and sodium acetate buffers of varying molarities $(0.01 \mathrm{M}, 0.25 \mathrm{M}$, and $0.50 \mathrm{M})$ and $\mathrm{pH}$ levels. Toxic extracts were also treated with the detergent, Triton $\mathrm{X}-100$, prior to ultrafiltration.

TLC plates were run with crude extracts alongside the molecular separations in order to more directly observe the amount of material at each filtration level. The butanol solvent system was used with ninhydrin and 0-tolidine.

The efficacy of the ultrafiltration membranes led to their routine use in partially purifying toxin. Not only could the membranes be used to separate out molecules higher in weight than the toxin, but molecules smaller than the toxin could be filtered through while the toxin was retained at a certain molecular size.

\section{Purification and Identification}

Organic solvents did not produce extraction of toxin, for the amounts used, in detectable levels.

The thin layer chromatographic methods produced separation of compounds, but the toxicity of any of these separations could not be confirmed as it was not possible to remove them from the Silica gel. The n-butanol solvent system provided the best resolution with little or no trailing. Ninhydrin and 0-tolidine were the only sprays tried that developed compounds on the TLC plates. 0-tolidine developed 6 spots on the TLC plates: a green spot that remained at the origin and 5 blue (amine positive) spots. Ninhydrin produced 3 spots: a blue spot at the origin and 2 purple spots 
(amine positive). There were no reactions with any of the following spray reagents: Jaffe, Benedict-Bahre, Sakaguchi, Weber, Diacety1- -Naptho1, Ehrlich's, NBD-chloride, and Fast Blue B. Ascending paper chromatography produced the best resolution and separation in the n-butanol solvent system but was not as good as the TLC medium. Ninhydrin developed five spots: a yellow-green spot at the solvent front, 3 purple (amine positive) spots, and a yellow spot that always remained at the origin. 0-tolidine developed 3 spots on paper: a yellow spot at the solvent front, a blue (amine positive) spot, and a yellow spot that remained at the origin. 
BIOGRAPHICAL DATA

Name: Thomas Lee Foxal1

Date of Birth: February 4, 1946

Place of Birth: Hartford, Connecticut

Secondary Education: Wethersfield High School

Wethersfield, Connecticut

Collegiate Education:

Lebanon Valley College

9/64-6/68 B.S. Biology

Annville, Penna.

University of Bridgeport $\quad 1 / 73-6 / 75$ M.S. Biology

Bridgeport, Conn.

University of New Hampshire 9/75-6/80 Ph.D. Zoology

Durham, N.H.

Honors and Awards:

Beta Beta Beta, Alpha Zeta Chapter

Phi Sigma, UNH Chapter

Sigma Xi, UNH Chapter

International Society on Toxinology

Positions Held:

Biology Instructor, Baltimore Public School System Baltimore, Md. 1969-70

Biology, Advanced Biology, Ecology Instructor Staples High School, Westport, Conn. 1970-75

Publications:

Foxa11, T. L., N. H. Shoptaugh, M. Ikawa and J. J. Sasner, Jr. Secondary Intoxication with PSP in Cancer irroratus. Proceedings of the Second International Conference on Toxic Dinoflagellate Blooms. Elsevier North Holland Press, 1978.

Foxa11, Thomas L. and J. J. Sasner, Jr. Effects of a hepatic toxin from the Cyanophyte Microcystis aeruginosa. Proceedings of the International Conference on The Water Environment: Algal Toxins and Health. U.S. Printing Office, 1980. 
Ikawa, Miyoshi, T. L. Foxa11, N. H. Shoptaugh, P. W. Carter and J. J. Sasner, Jr. Fluorometric studies on the detection and determination of the toxins of Aphanizomenon flos-aquae. Proceedings of the International Conference on the Water Environment: Algal Toxins and Health. U.S. Printing Office, 1980.

Shoptaugh, Nancy H., M. Ikawa, T. L. Foxal1 and J. J. Sasner, Jr. A fluorometric technique for the detection and distribution of paralytic shellfish poisons. Proceedings of the International Conference on the Water Environment: Algal Toxins and Health. U.S. Printing Office. 1980.

Sasner, Jr., John J., M. Ikawa, T. L. Foxa11 and W. H. Watson. Studies on Aphantoxins from Aphanizomenon flos-aquae in New Hampshire. Proceedings of the International Conference on the Water Environment: Algal Toxins and Health. U.S. Pringing office. 1980. ,

Ecker, Marilyn M., T. L. Foxall and J. J. Sasner, Jr. Morphology of toxic versus non-toxic strains of Aphanizomenon flos-aquae. Proceedings of the International Conference on the Water Environment: Algal Toxins and Health. U.S. Printing Office. 1980 . 